
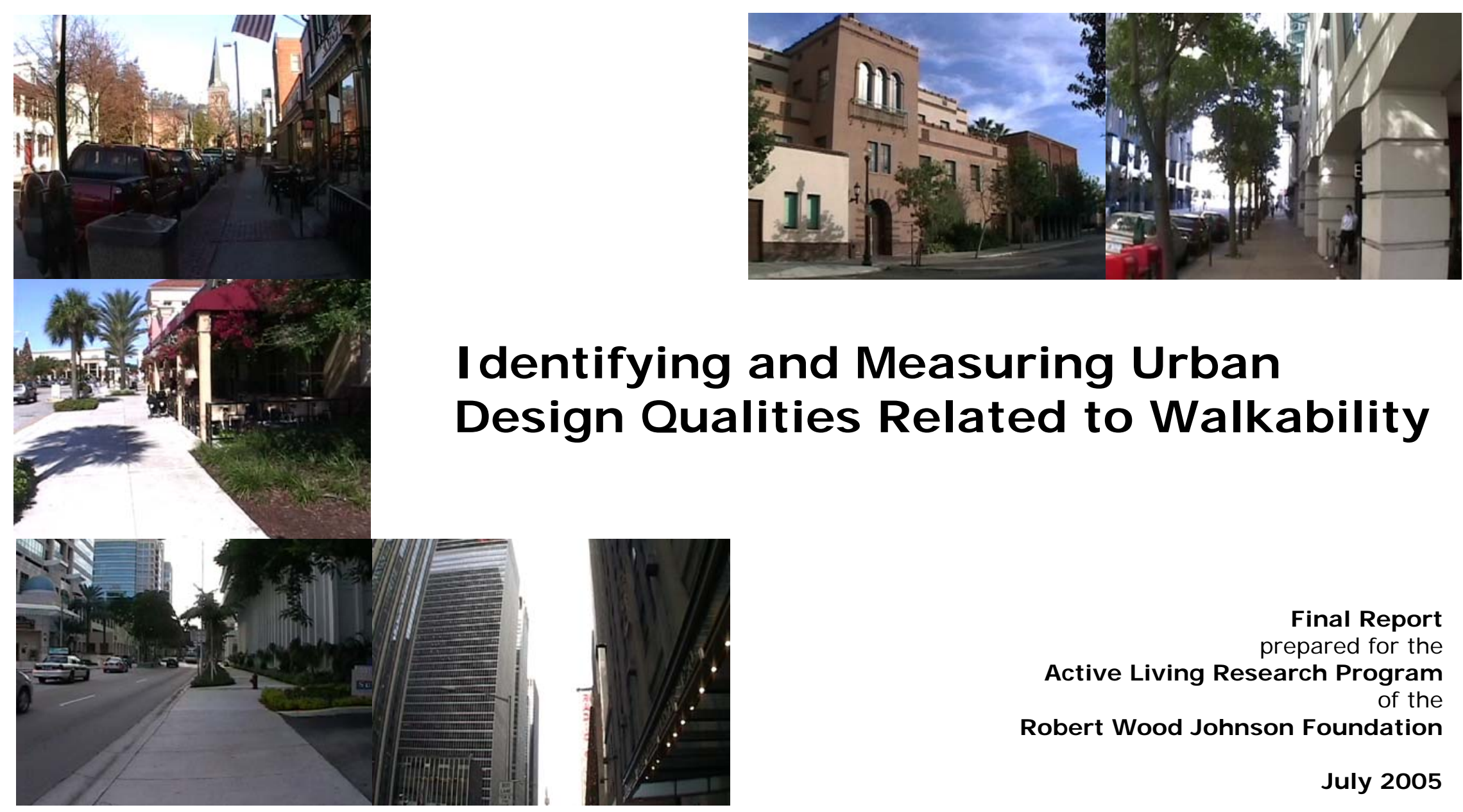

\title{
I dentifying and Measuring Urban Design Qualities Related to Walkability
}

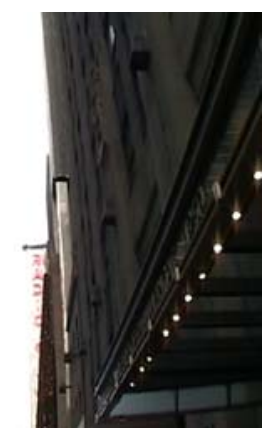

Final Report prepared for the Active Living Research Program of the Robert Wood Johnson Foundation J uly 2005 


\section{Measuring Urban Design Qualities Related to Walkability}

\section{Final Report prepared for the \\ Active Living Research Program of the}

Robert Wood Johnson Foundation

Reid Ewing and Otto Clemente National Center for Smart Growth Research and Education

University of Maryland

Susan Handy Department of Environmental Science and Policy

University of California, Davis

Ross C. Brownson Prevention Research Center Saint Louis University School of Public Health

Emily Winston Institute of Transportation Studies University of California, Davis

June 2005 


\section{Table of Contents}

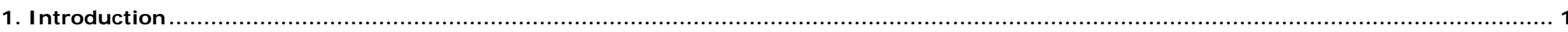

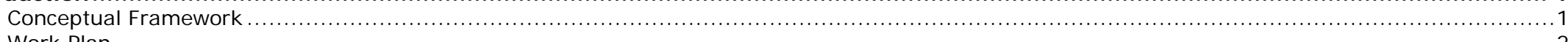

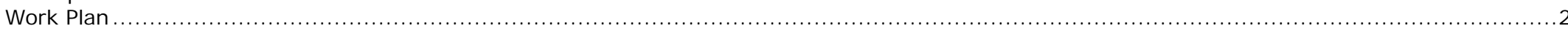

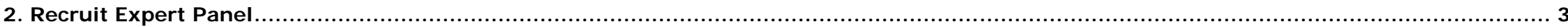

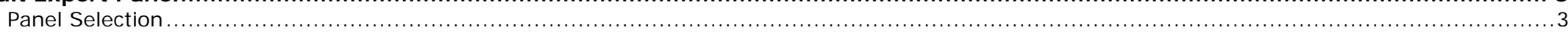

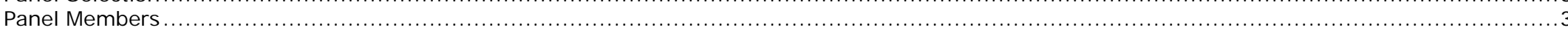

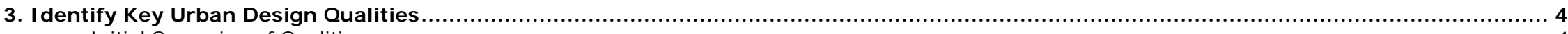

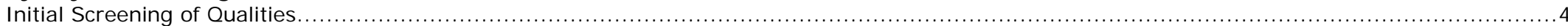

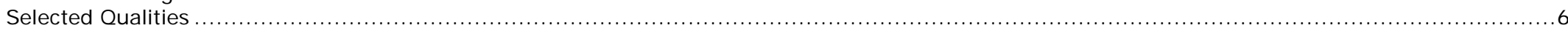

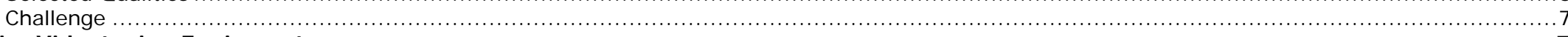

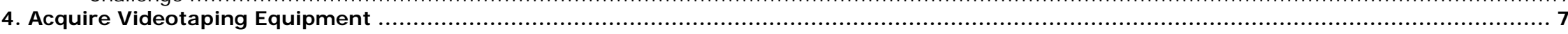

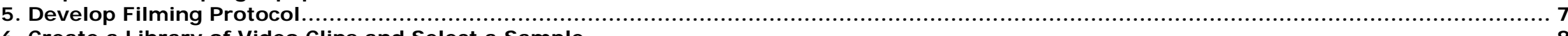

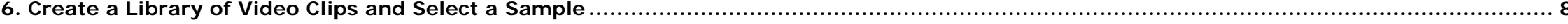

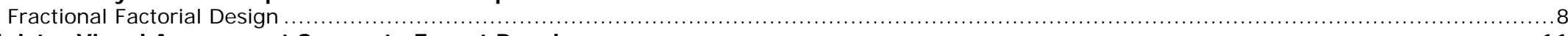

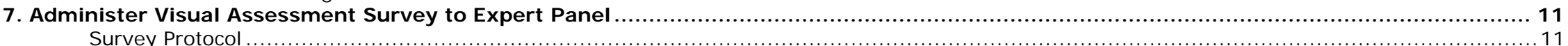

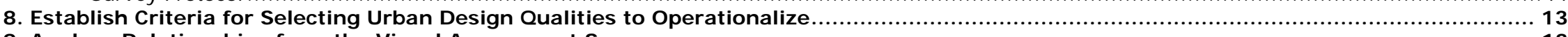

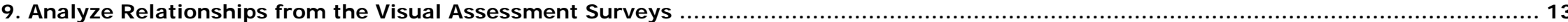

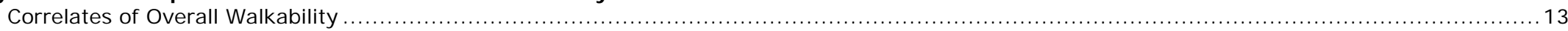

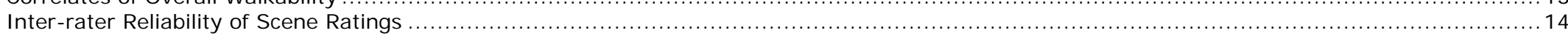

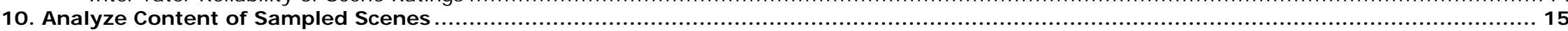

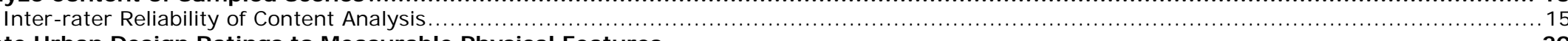

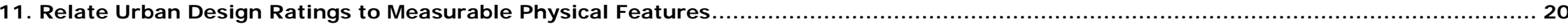

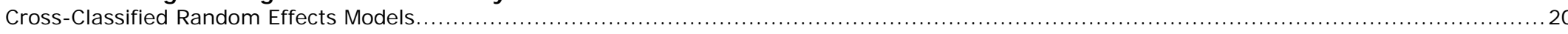

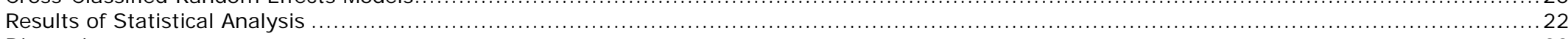

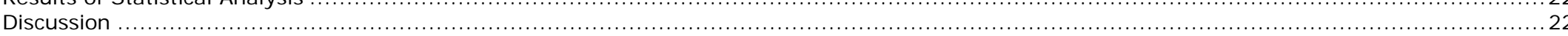

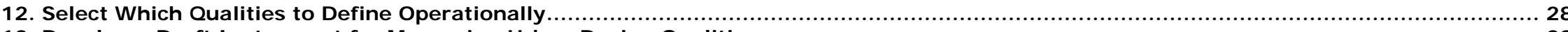

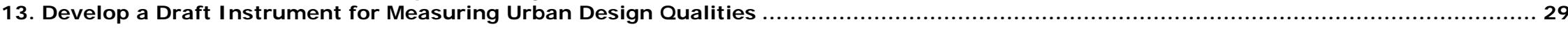

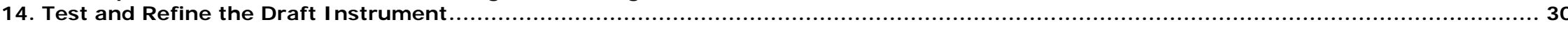

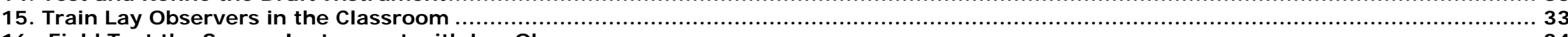

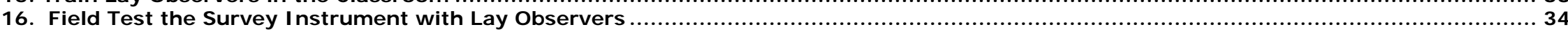

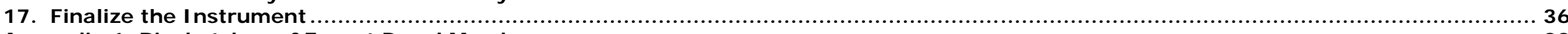

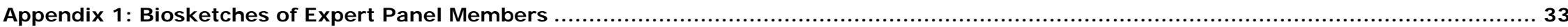

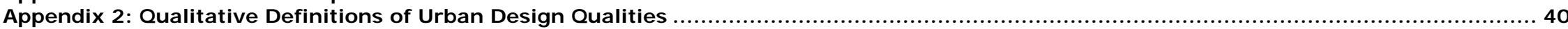

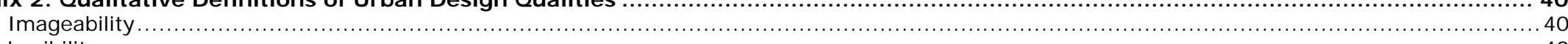

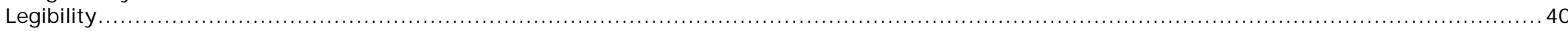

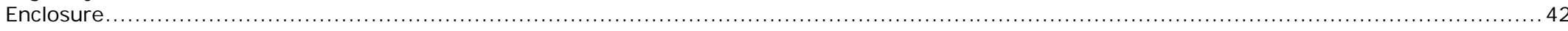

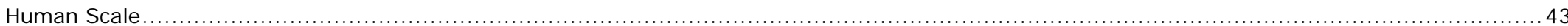

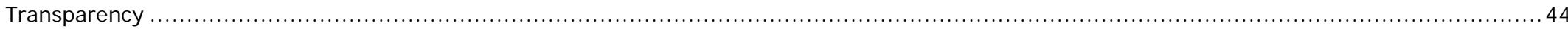

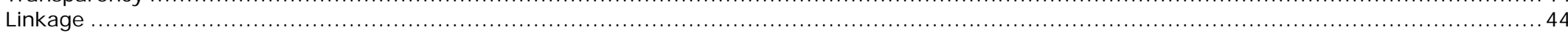

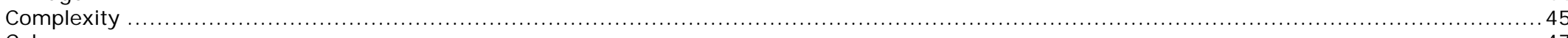

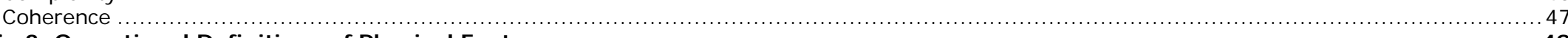

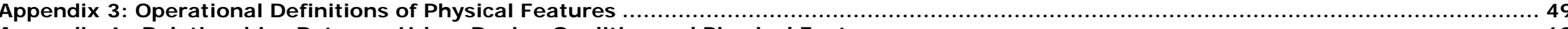

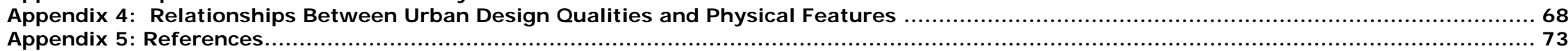




\section{I dentifying and Measuring Urban Design Qualities Related to Walkability}

\section{I ntroduction}

A growing body of research provides evidence of a link between the built environment and active living.

However, to date, the measures used to characterize the built environment have been mostly gross qualities such as neighborhood density and street connectivity (see reviews by Ewing and Cervero 2001; Handy 2004; and Ewing 2005).

The urban design literature points to subtler qualities that may influence choices about active travel and active leisure time. These qualities will be referred to as perceptual qualities of the urban environment or alternately, just as urban design qualities. The urban design literature presumes that these qualities are important for walkability, without much empirical evidence. Until urban design qualities can be measured, this presumption will remain untested.
This Round I Active Living Research Project has sought to develop operational definitions and measurement protocols for nine intangible qualities of the urban environment. It has been largely successful and forms the basis for further work. Operational definitions and measurement protocols have been developed for six of nine perceptual qualities, specifically: imageability, visual enclosure, human scale, transparency, complexity, and tidiness.

To aid in the dissemination of the measures, we have developed a field survey instrument. This instrument will be tested and refined, and lay observers will be trained in its use. With valid and reliable measures available, and relatively easy to use, travel behavior researchers and physical activity researchers will be better able to study relationships between the built environment and walking behavior.

\section{Conceptual Framework}

The conceptual model underlying this study considers the role of perceptions as they intervene (or mediate) between the physical features of the environment and walking behavior. Physical features of the built environment influence the quality of the walking environment both directly and indirectly through the perceptions and sensitivities of individuals. Our study focuses on urban design qualities, qualities of the environment that depend on physical features but reflect the general way in which people perceive and interact with the environment.

These perceptual qualities are different from qualities such as sense of comfort, sense of safety, level of interest that reflect how an individual reacts to a place-how they assess the conditions there, given their own preferences and perspectives. Perceptions are just that, perceptions. They may produce different reactions in different people. They may be assessed with a degree of objectivity by outside observers.

All of these factors-physical features, perceptual qualities, and individual reactions-influence the way that an individual feels about the environment as a place to walk. By measuring these intervening 
variables, we can better understand the relationship between physical

features of the built environment and walking behavior.

\section{Work Plan}

Our work plan consisted of 16 tasks:

- Recruit expert panel.

- Identify key urban design qualities.

- Acquire videotaping equipment.

- Develop filming protocol.

- Create library of video clips and select a sample.

- Administer visual assessment survey to expert panel.

- Establish criteria for selecting which urban design qualities to operationalize.

- Analyze relationships from the visual assessment survey.

- Analyze content of sampled scenes.

- Relate urban design quality ratings to measured physical features.

- Select urban design qualities to define operationally.

- Develop a draft instrument for operationalizing urban design qualities.

- Test and refine the draft instrument.
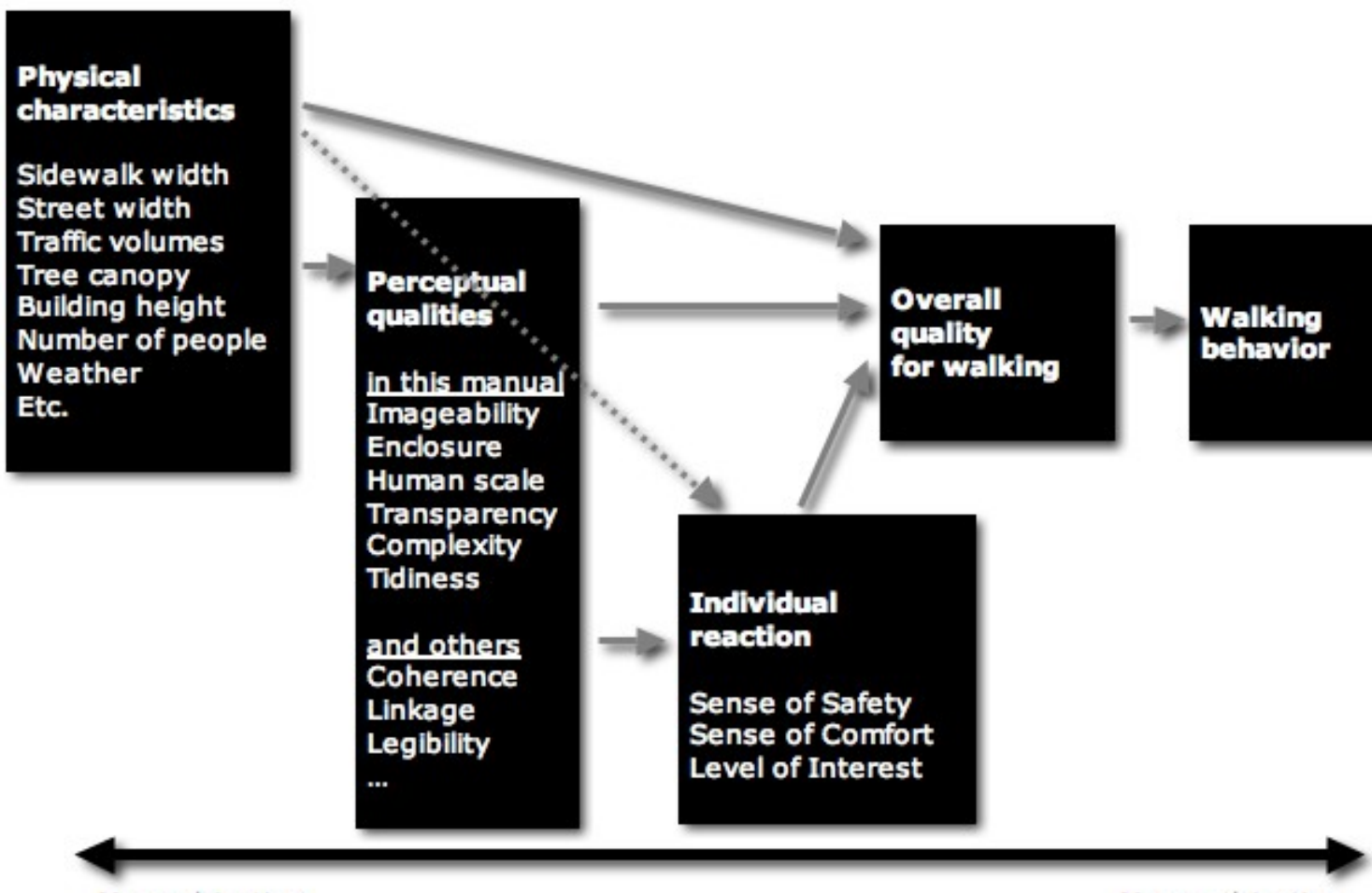

More objective

More subjective

Figure 1: Conceptual Framework 
- Train and certify lay observers in classroom.

- Provide field training in use of the instrument.

- Finalize the instrument.

Tasks are described in subsequent sections of this report.

\section{Recruit Expert Panel}

A critical part of our workplan was to assemble a panel of urban design and planning experts. The panel members helped define perceptual qualities of urban scenes, rated different scenes with respect to these qualities in a visual assessment-style survey, submitted to interviews as they assigned their ratings to provide the research team with qualitative insights into their rating criteria, met to discuss ways of measuring perceptual qualities, and reviewed and commented on the draft field observation manual which presented the measurement instrument in all its detail. Their views on the character and importance of different urban design qualities became the gold standard for this study.

\section{Panel Selection}

The panel was selected through a networking process in which the principal investigators (PIs) called colleagues and asked for

nominations. Experts identified in this manner were asked for additional nominations, and so the process proceeded until all 10 openings were filled.

The criteria for panel membership were as follows. First and foremost, panel members had to have knowledge of urban design concepts and expertise in urban design or related fields that would support their subjective judgments.

Second, so their opinions would carry weight, the panel members had to acknowledged leaders in their respective fields. This is an exceptionally creative and prominent group.

Finally, the panel members had to represent a variety of different perspectives. Having both planning and public health represented among the PIs ensured that different professional networks would be tapped. An effort was made to achieve a balance between urban designers and other planning professionals, and between those with a "new urbanist" bent (referring to a movement in design and planning that has its own design paradigm) and those with a more conventional orientation toward urban design.

\section{Panel Members}

The 10 expert panel members selected through this process were:

Victor Dover - urban designer Principal-in-Charge, Dover, Kohl \& Partners Town Planning, South Miami FL

Geoffrey Ferrell - urban

designer/code expert - Geoffrey Ferrell Associates, Washington, D.C.

Mark Francis - landscape architect Professor, Department of Landscape Architecture (check on this) University of California, Davis, CA

Michael Kwartler -

architect/simulations expert -

Director, Environmental Simulation

Center, New York, NY

Rob Lane - urban designer - Director of the Design Program, Regional Plan Association, New York, NY

Anne Vernez Moudon - urban designer/planner - Professor of Architecture, Landscape Architecture, and Urban Design \& Planning, 
University of Washington, Seattle, WA

Tony Nelessen - urban designer President, A. Nelessen Associates, Inc., Princeton, NJ and Associate Professor of Urban Planning, Rutgers University, New Brunswick, NJ

John Peponis - architect/space syntax expert - Associate Professor of Architecture, College of Architecture, Georgia Institute of Technology, Atlanta, GA

Michael Southworth - urban designer - Professor, Department of City and Regional Planning and Department of Landscape Architecture, University of California, Berkeley, CA

Dan Stokols - social ecologist Professor, School of Social Ecology, University of California, Irvine, CA

Biosketches of expert panel members are contained in Appendix 1.

\section{I dentify Key Urban Design Qualities}

In terms of the public realm, no element of the urban environment is more important than streets. This is where active travel to work, shop, eat out, and engage in other daily

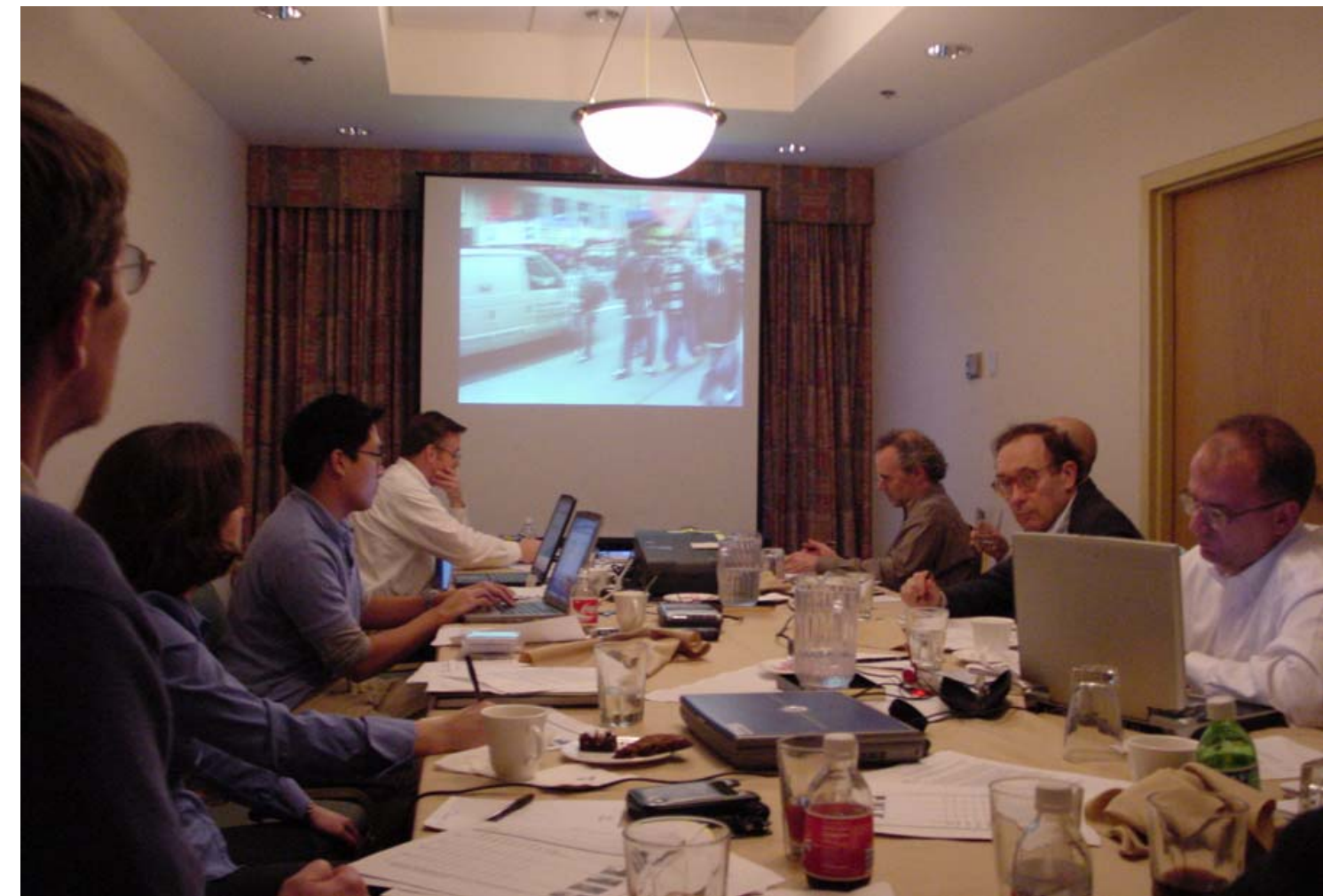

Figure 2: Visual Assessment Survey During Expert Panel Meeting

activities takes place, and where walking for exercise mostly occurs.

Parks, plazas, trails, and other public places have a role in physical activity, but due to budget and time limitations, this study deals only with the perceptual qualities that make one street more walkable than another.

\section{I nitial Screening of Qualities}

Key perceptual qualities of the urban environment were identified based on a review of the urban design literature. At different points in the 
careers, two of the PIs have had occasion to review the urban design literature (see Ewing, 1996 and Handy, 1992). Perceptual qualities figure prominently in such classics as:

Alexander, C., S. Ishikawa, and M. Silverstein. 1977. A Pattern Language - Towns Buildings Construction.

Oxford University Press, New York.

Arnold, Henry. 1993. Trees in Urban Design, Van Nostrand Reinhold, New York.

Cullen, Gordon. 1961. The Concise Townscape. Reed Educational and Professional Publishing, London.

Gehl, Jan. 1987. Life Between Buildings - Using Public Space. Van Nostand Reinhold, New York.

Hedman, Richard. 1984.

Fundamentals of Urban Design.

American Planning Association,

Chicago, IL.

Jacobs, Allan. 1993. Great Streets. MIT Press, Cambridge, MA.

Jacobs, Jane. 1961. The Death and Life of Great American Cities. Random House, New York.
Lynch, Kevin. 1960. The Image of the City. Joint Center for Urban Studies, Cambridge, MA.

Rapoport, Amos. 1990. History and Precedent in Environmental Design. Kluwer Academic Publishers, Plenum Press, New York.

Sitte, Camillo. 1889. City Planning According to Artistic Principles. Verlag von Carl Graeser, Vienna. (Complete translation in G.R. Collins, C.C. Collins, Camillo Sitte.1986. The Birth of Modern City Planning, Rizzoli International Publications, New York).

Trancik, Roger. 1986. Finding Lost Space-Theories of Urban Design. Van Nostrand Reinhold, New York.

Unwin, Raymond.1909. Town Planning in Practice. T. Fisher Unwin, Ltd., London. (Reissued by Princeton Architectural Press, New York, 1994).

Whyte, William H. 1988. CityRediscovering the Center, Doubleday, New York.

The research team has also reviewed the visual assessment literature, which attempts to measure how individuals perceive their environments and better understand what individuals value in their environments. Partial listing of this voluminous empirical literature is provided in Ewing (2000) and updated in Ewing et al. (in press). These literature reviews go beyond the boundaries of urban design to the fields of architecture, landscape architecture, park planning, environmental psychology, etc., as perceptual qualities of the environment figure prominently in these fields as well.

The long list of perceptual qualities described in literature includes: adaptability, ambiguity, centrality, clarity, compatibility, comfort, complementarity, continuity, contrast, deflection, depth, distinctiveness, diversity, dominance, expectancy, focality, formality, identifiability, intelligibility, interest, intimacy, intricacy, meaning, mystery, naturalness, novelty, openness, ornateness, prospect, refuge, regularity, rhythm, richness, sensuousness, singularity, spaciousness, territoriality, texture, unity, upkeep, variety, visibility, and vividness.

We focused on eight urban design qualities that appeared distinct and 
important from both the qualitative literature and quantitative attempts to measure what is valued by users of urban space: imageability, legibility, visual enclosure, human scale, transparency, linkage,

complexity, coherence. The eight are defined in the next section. A ninth quality, tidiness, was added when a review of video clips indicated that one potentially important dimension of scenes simply was not captured by the eight qualities selected initially.

\section{Selected Qualities}

A definitional piece was written on perceptual qualities of the urban environment. Definitions were refined, and references were added, with help from the expert panel.

Short definitions are supplied below. Longer discussions are provided in Appendix 2.

\section{I mageability}

I mageability is the quality of a place that makes it distinct, recognizable, and memorable. A place has high imageability when specific physical elements and their arrangement capture attention, evoke feelings, and create a lasting impression.

\section{Legibility}

Legibility refers to the ease with which the spatial structure of a place can be understood and navigated as a whole. The legibility of a place is improved by a street or pedestrian network that provides travelers with a sense of orientation and relative location and by physical elements that serve as reference points.

\section{Enclosure}

Enclosure refers to the degree to which streets and other public spaces are visually defined by buildings, walls, trees, and other elements. Spaces where the height of vertical elements is proportionally related to the width of the space between them have a room-like quality.

\section{Human Scale}

Human scale refers to a size, texture, and articulation of physical elements that match the size and proportions of humans and, equally important, correspond to the speed at which humans walk. Building details, pavement texture, street trees, and street furniture are all physical elements contributing to human scale.

\section{Transparency}

Transparency refers to the degree to which people can see or perceive what lies beyond the edge of a street or other public space and, more specifically, the degree to which people can see or perceive human activity beyond the edge of a street or other public space. Physical elements that influence transparency include walls, windows, doors, fences, landscaping, and openings into midblock spaces.

\section{Linkage}

Linkage refers to physical and visual connections from building to street, building to building, space to space, or one side of the street to the other which tend to unify disparate elements. Tree lines, building projections, marked crossings all create linkage. Linkage can occur longitudinally along a street or laterally across a street.

\section{Complexity}

Complexity refers to the visual richness of a place. The complexity of a place depends on the variety of the physical environment, specifically the numbers and kinds of buildings, architectural diversity and ornamentation, landscape elements, 
street furniture, signage, and human activity.

\section{Coherence}

Coherence refers to a sense of visual order. The degree of coherence is influenced by consistency and complementarity in the scale, character, and arrangement of buildings, landscaping, street furniture, paving materials, and other physical elements.

\section{Challenge}

Our challenge was to move from these highly subjective definitions of urban design qualities to operational definitions which capture the essence of each quality and can be measured with a degree of reliability across raters, including those without training in urban design.

\section{Acquire Videotaping Equipment}

After a survey of equipment options, we settled on the digital video camcorder because it would allow extended video clips and easy downloads to a computer. The Canon ZR70 MC Mini DV Camcorder was selected for its moderate price and specific features: ability to shoot both video and stills; wide angle attachment; precision optical zoom: image stabilizer; and extended battery life.

Three identical video camcorders were acquired so the video clips could be shot concurrently by the three co$\mathrm{PIs}$ and research assistants in their distant geographic settings. Detailed specifications for the chosen camcorder can be found at

http://www.canondv.com/zr70mc/ind ex.html.

\section{Develop Filming Protocol}

With five individuals shooting clips, a consistent filming protocol had to be followed to ensure that reactions to street scenes were not biased by different filming techniques. A great deal of experimentation and dialogue among the PIs went into the development of a protocol that would mimic the experience of pedestrians. Pedestrians are usually in motion, sway a bit as they walk, have peripheral vision, and tend to scan their environments.

For example, one set of early trials compared:

first clip - about 60 seconds - fast 180 degree pan and back again slow walk forward - fast 180 degree pan and back again second clip - about 40 seconds slow 180 degree pan and back again

third clip - about 20 seconds - slow 360 degree pan

fourth clip - about 55 seconds - slow 360 degree pan - slow walk forward - slow 360 degree pan

fifth clip - about 55 seconds - slow 360 degree horizontal pan with slow vertical pans in each direction

We quickly realized that much of the environment relevant to a pedestrian was not captured by stationary clips. Slow forward motion became standard despite the wobble this occasioned. The image stabilizer was of only assistance. Both continuous and intermittent panning horizontally were tested. The continuous pan covered more ground in a given time. Vertical panning was added to approximate peripheral vision and capture vertical elements that might attract attention.

Filming was extended for longer periods so as to take in more of the street. The beginning of the block was established as the consistent starting point. We considered the possibility of continuing to film until 
the end of the block became visible but realized this would consume too much time on longer blocks. At some point, the wide pan to the rear was dropped as disorienting. The full pan to the right was also dropped since it brought buildings uncomfortably close.

The final filming protocol became:

Have video camcorder set on high resolution. Using the "Canon Wide Attachment WA-30.5" lens and zooming out as far as possible manually, proceed as follows:

- start about 20 feet from the beginning of the block on the outside of the sidewalk

- walk slowly forward in the direction of adjacent traffic at a speed of approximately $1 \mathrm{mph}$

- as you move forward, pan slowly and continuously following the same sequence
- looking straight ahead, pan down 30 degrees, pan up 30 degrees, back to level

- pan 45 degrees right, pan up to the top of adjacent buildings or trees, and back to level

- pan 135 degrees left to the opposite side of the street, pan up to the top of opposite buildings or trees, and back to level

- pan 90 degrees right, to straight ahead

- repeat the sequence for a total of two complete pans

\section{Create a Library of Video Clips and Select a Sample}

Working off a shoot list, more than 200 clips were filmed in dozens of cities around the United States. The shoot list was generated according to a fractional factorial design described momentarily. Diversity of street scenes was ensured by the different regional settings of the PIs, and the travels of PIs on other business during the course of the study.

While they succeed to varying degrees, all streets included in the sample attempt to accommodate pedestrians. All could be characterized as urban. All have sidewalks. All offer pedestrian amenities of some sort such as landscaping, pedestrian lighting, street furniture, and trip destinations within view.

\section{Fractional Factorial Design}

Scenes were shot and ultimately selected for the visual assessment survey using a fractional factorial design. We wanted to capture relevant combinations of the eight urban design qualities being operationalized (tidiness was added later). Without variation across the qualities, it would be impossible to tease out the contributions of physical features to the urban design quality ratings of our expert panel. 
A common experimental design is one in which all input factors are set at two levels each. In the literature, these levels are referred to as 'high' and 'low' or ' +1 ' and ' -1 ', respectively. A design with all possible high/low combinations of all the input factors is called a full factorial design in two levels.

If there are $\mathrm{k}$ factors, each at 2 levels, a full factorial design requires $2^{k}$ separate runs (in this case, the "runs" are individual video clips). Even if the number of factors, $k$, in a design is small, the $2^{k}$ runs specified for a full factorial can quickly become very large. With two levels and eight factors, a full factorial design requires 256 runs.

The solution to this problem is to use only a fraction of the runs specified by the full factorial design. A fractional factorial design is considered a better choice when there are five or more factors, as there were in this study. A fractional factorial design is one in which only a fraction of the treatment combinations required for the full factorial experiment is selected. That fraction may be $1 / 2,1 / 4$, etc. of the runs called for by the full factorial. Properly chosen fractional factorial designs for 2-level experiments have
Table 1: $\mathbf{2}^{8-4}$ Fractional Factorial Design That Served as a Guide for Sampling Video Clips

\begin{tabular}{|c|c|c|c|c|c|c|c|c|}
\hline & I mageability & Enclosure & $\begin{array}{l}\text { Human } \\
\text { Scale }\end{array}$ & Transparency & Linkage & Complexity & Coherence & Tidiness \\
\hline $\begin{array}{l}\text { clip } \\
1\end{array}$ & low & low & low & low & low & low & low & low \\
\hline $\begin{array}{l}\text { clip } \\
2\end{array}$ & high & low & low & low & low & high & high & high \\
\hline $\begin{array}{l}\text { clip } \\
3\end{array}$ & low & high & low & low & high & low & high & high \\
\hline $\begin{array}{l}\text { clip } \\
4\end{array}$ & high & high & low & low & high & high & low & low \\
\hline $\begin{array}{l}\text { clip } \\
5\end{array}$ & low & low & high & low & high & high & high & low \\
\hline $\begin{array}{l}\text { clip } \\
6\end{array}$ & high & low & high & low & high & low & low & high \\
\hline $\begin{array}{l}\text { clip } \\
7\end{array}$ & low & high & high & low & low & high & low & high \\
\hline $\begin{array}{l}\text { clip } \\
8\end{array}$ & high & high & high & low & low & low & high & low \\
\hline $\begin{array}{l}\text { clip } \\
9\end{array}$ & low & low & low & high & high & high & low & high \\
\hline $\begin{array}{l}\text { clip } \\
10\end{array}$ & high & low & low & high & high & low & high & low \\
\hline $\begin{array}{l}\text { clip } \\
11\end{array}$ & low & high & low & high & low & high & high & low \\
\hline $\begin{array}{l}\text { clip } \\
12\end{array}$ & high & high & low & high & low & low & low & high \\
\hline $\begin{array}{l}\text { clip } \\
13\end{array}$ & low & low & high & high & low & low & high & high \\
\hline $\begin{array}{l}\text { clip } \\
14\end{array}$ & high & low & high & high & low & high & low & low \\
\hline $\begin{array}{l}\text { clip } \\
15\end{array}$ & low & high & high & high & high & low & low & low \\
\hline $\begin{array}{l}\text { clip } \\
16 \\
\end{array}$ & high & high & high & high & high & high & high & high \\
\hline
\end{tabular}




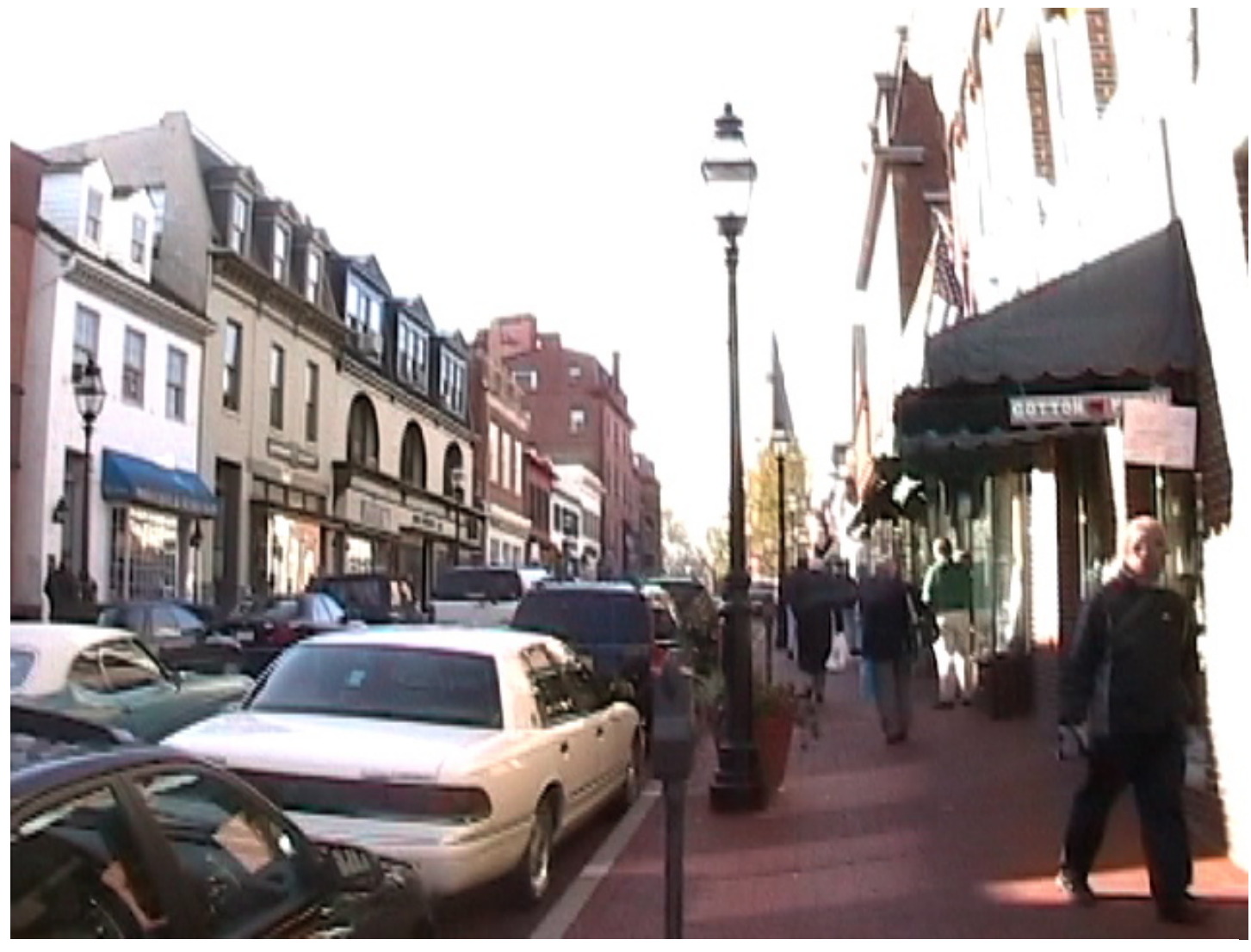

Figure 3: Best Match for a Run that Required High Values of All Eight Qualities

the desirable properties of being both balanced and orthogonal.

To choose our samples, one PI and his RA rated clips as "high" or "low" with respect to the eight perceptual qualities (tidiness not included). From the larger set, 32 clips were selected that best matched the combinations of high/low values in a $2^{8-3}$ fractional factorial design. Some of clips matched high/low patterns perfectly. Others matched on only seven, six, or even five of the qualities, rather than all eight. Urban design qualities tend to co-vary (that is, appear in certain combinations of high and low values), making perfect matches unlikely starting with any practically sized set of clips. These carefully selected clips served as our sample in the subsequent visual assessment survey. The $2^{8-3}$ sample allowed us to capture the main effects of each urban design quality on overall walkability, plus two-factor interaction effects.

To expand the sample size for analytical purposes, 16 additional clips were later selected. For this sample, we sought to match the $2^{8-4}$ fractional factorial design (as shown in Table 1).

To illustrate, we found a clip with high values of all eight urban design qualities that perfectly matched the corresponding $2^{8-4}$ run (clip 16 in Table 1-shown in Figure 3). But we had to settle for a clip that matched values of only seven qualities for the $2^{8-4}$ run that required high values of imageability, human scale, linkage and tidiness and low values of other qualities (clip 6-shown in Figure 4). We, again, also settled for a clip that 
matched only seven qualities for the run that is basically the opposite to clip 6 with high values for enclosure, transparency, complexity and

coherence (clip 11-shown in Figure 5). Although we weren't able to exactly match the fractional factorial design in all cases, following the design as close as possible resulted in the selection of clips that are distinctly different as the following figures illustrate. Where ratings for two or more clips matched factorial design equally well, clips were selected to maximize geographic diversity.

\section{Administer Visual Assessment Survey to Expert Panel}

The first wave of the visual assessment survey ( 32 clips) was conducted electronically. The sample of video clips was recorded in random order onto DVDs, and the DVDs were distributed to expert panel members.

A telephone survey was then conducted in which the panel member and a research team member viewed each clip concurrently, the panel member assigned scores to each clip and commented on the specific features of scenes that produced high or low

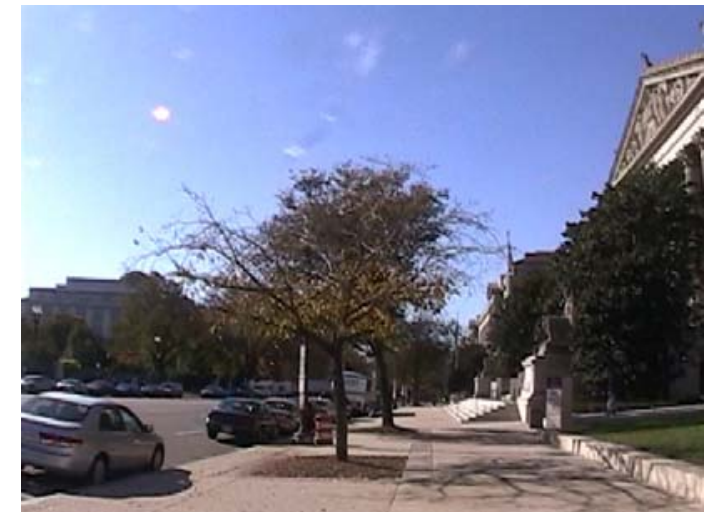

Figure 4: Best Match for a Run that

Required High Values of I mageability,

Linkage, and Tidiness

scores, and the team member recorded scores and taped

comments. Thus, there was a quantitative and qualitative element to the survey. The qualitative element would assist the research team in identifying physical features of scenes worth measuring in the subsequent content analysis, and would provide a fallback for operationalizing urban design qualities if the quantitative analysis failed.

To expand the sample, a second visual assessment survey (16 additional clips) was conducted faceto-face at a meeting of the expert panel. For this survey, clips were also in random order. Panel

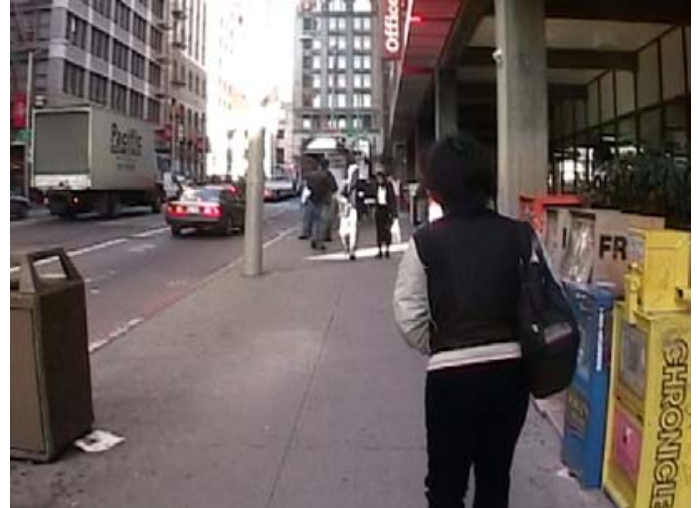

Figure 5: Best Match for a Run that Required High Values of Enclosure, Transparency, and Complexity

members who could not attend the meeting were sent DVDs and subsequently surveyed by phone.

\section{Survey Protocol}

The three PIs and their RAs divided up responsibility for conducting phone surveys with the expert panel members. Therefore, as with the shooting of video clips, it was necessary to establish a standard protocol for the interviews so as to ensure consistency and avoid possible bias in responses. Some experimentation was involved with this protocol as well.

The final protocol was as follows: 
Before the interviews, contact panelists and ask them to review the work plan for the project. Also ask them to have printed copies of the survey form and perceptual qualities definitional piece available during the survey. These should be on their desks during the survey, the former to be completed and the latter as a reference. Panelists will be using their personal computers to view the DVD, and so will need hard copies of the survey form on which to record their ratings.

Begin interviews by asking if panelists have any questions or feedback on the purpose of the project, purpose of the visual assessment survey, the survey instrument itself, or the urban design qualities definitional piece. We have added still photos of scenes to the rating form. With the photos as memory jogs, panelists can refer back to earlier clips for benchmarks as they proceed through the survey. We have also added a final column to the form, in which panelists will rate the overall quality of the walking environment for each clip.

Conduct interviews on the speaker phone, recording the entirety for later reference. An inexpensive tape recorder produces adequate sound quality. Monitor the tape recorder throughout the interview to make sure it does not run out of tape. It did so twice in our pilot session.

To show panelists the range of values represented by the sample (so they leave room for ouliers at the top and bottom of the Likert scale), view clips $3,7,15,16$ before starting the rating process. Mention that a consistent filming protocol was used throughout which, we hope, gives them a complete picture of the streetscape. Ask them if they have any questions or feedback on the clips.

Make sure panelists have the sound on their computers turned on for the interviews. Ratings can and should be affected by sound as well as sight (so in this sense, this isn't a pure visual assessment survey).

Explain to the panelists that each clip will be played two or more times.

Have them use the first pass to

familiarize themselves with the scene and comment on the streetscape in open-ended fashion. On subsequent passes, have them assign quantitative ratings to all perceptual qualities on a 1-5 Likert scale. Ask them to rate in whole numbers on the individual perceptual qualities, but allow them to rate with one decimal place precision on overall walkability. Make sure they provide reasons, articulate criteria, and/or define relevant physical features for each rating. One key reason per rating will be sufficient.

Concurrently, you and the panelists will play clips in the order they appear on the DVD, which was randomized. Move through the clips at panelists' desired pace. Since their comments are being tape recorded, it will not be necessary to take notes on qualitative reactions to clips. But ask panelists to give you their quantitative ratings on the second pass through each clip. You will be recording their ratings on your survey form, as they concurrently record ratings on their survey forms.

When all 32 clips have been rated, ask them to go back on their own to finalize their ratings in light of the entire sample. Ask them to email the final rating form to you in any event. to check that you have correctly recorded ratings given over the phone. If every panelist grades harder on later clips, we can control for "order of viewing effects" statistically. If not, we will have to rely on their own adjustments upon 
re-viewing to achieve intra-rater reliability.

These are exceptionally knowledgeable people who will recognize many of the streets. You can confirm but don't identify places so as not to bias ratings with positive or negative associations.

\section{Establish Criteria for Selecting Urban Design Qualities to Operationalize}

We realized early on that not all urban design qualities could be defined operationally for

streetscapes. Appendix 2 includes a discussion of measurement possibilities for the first eight qualities. Some are clearly more amenable to measurement than are others.

To decide which urban design qualities were ultimately defined operationally, five criteria were established:

(1) The urban design quality was judged by the expert panel to have a statistically significant relationship to overall walkability ratings ( $p \leq 0.05$ ).
(2) The urban design quality was rated by the expert panel with at least a moderate degree of inter-rater reliability $(I C C \geq 0.4)$.

(3) The total variance in ratings of the urban design quality was explained to at least a moderate degree in terms of measurable physical features of scenes (explained portion $\geq 0.3$ )

(4) The portion of total variance attributable to scenes was explained to a substantial degree in terms of physical features of scenes (explained portion $\geq 0.6$ )

(5) All physical features related to ratings of a particular urban design quality were measured with at least a moderate degree of inter-rater reliability (ICC $\geq 0.4)$, excluding those for which ICC values could not be computed.

\section{Analyze Relationships from the Visual Assessment Surveys}

Results of the visual assessment surveys were pooled, and analyses were performed with expert panel ratings in connection with criteria (1) and (2) of the preceding section.

\section{Correlates of Overall Walkability}

Using mean values for the 48 video clips, we found that overall walkability is directly and significantly related to each urban design quality individually. The analysis is complicated, however, by the fact that eight of the nine qualities (the exception being tidiness) are collinear. Tolerance values were unacceptably low when all variables were included in a regression at once.

Linkage and legibility appeared to be largely functions of the other urban design qualities, so they were dropped from further consideration. Of the remaining variables, human scale had the strongest relationship to overall walkability almost regardless of what combination of variables was tested. Tidiness, and to a lesser extent, transparency, enclosure, and imageability, were somewhat independent of human scale, proved significant at the 0.10 level in most model runs, and improved the explanatory power of the model (the adjusted R-squared). Coherence was ultimately dropped because it proved insignificant and reduced the explanatory power of the model. Complexity was ultimately dropped even though significant in some model runs, because it altered 
relationships between other variables and overall walkability, and because it had a low tolerance value itself.

The best-fit equation is presented in Table 2. Perceptual qualities explain more than 95 percent of the variation in mean overall walkability, according to our expert panel. All qualities are directly related to overall walkability, and all are significant at conventional levels except tidiness, which falls just below the 0.10 level. Based on their t-statistics, human scale ranks first in significance as a determinant of overall walkability, imageability second, enclosure third, transparency fourth, and tidiness a distant fifth.

\section{Inter-rater Reliability of Scene} Ratings

Various statistical techniques may be used to assess inter-rater reliability in studies like this, where multiple individuals independently rate the same set of cases. For assessing inter-rater agreement, intra-class correlation coefficients (ICCs) are more appropriate than simple correlation coefficients. Simple correlation coefficients are sensitive only to random error (chance factors), while ICCs are sensitive to both random error and systematic error (statistical bias). For example,

Table 2: Regression Model for Overall Walkability

\begin{tabular}{lllll}
\hline Variable & Coefficient & $\begin{array}{l}\text { Standardized } \\
\text { Coefficient }\end{array}$ & t-statistic & p-value \\
\hline constant & -0.226 & & -1.503 & 0.140 \\
human scale & 0.411 & 0.420 & 5.814 & 0.000 \\
transparency & 0.137 & 0.149 & 2.366 & 0.023 \\
tidiness & 0.070 & 0.059 & 1.598 & 0.117 \\
enclosure & 0.140 & 0.157 & 2.504 & 0.016 \\
imageability & 0.307 & 0.310 & 5.153 & 0.000 \\
\hline $\mathrm{N}$ & 48 & & & \\
R-square & .959 & & & \\
Adjusted R- & .954 & & & \\
square & & & & \\
\hline
\end{tabular}

Table 3: I nter-rater Reliability for Ratings of Perceptual Qualities

\begin{tabular}{llll}
\hline & $\begin{array}{l}\text { Intra-class } \\
\text { Correlation } \\
\text { Coefficient }\end{array}$ & $\begin{array}{l}\mathbf{9 5 \%} \\
\text { Confidence } \\
\text { Interval of I CC }\end{array}$ & $\begin{array}{l}\text { Cronbach's } \\
\text { Alpha }\end{array}$ \\
\hline imageability & .494 & $.385-.618$ & .930 \\
legibility & .380 & $.276-.509$ & .895 \\
enclosure & .584 & $.478-.697$ & .945 \\
human scale & .508 & $.399-.630$ & .928 \\
transparency & .499 & $.390-.622$ & .926 \\
linkage & .344 & $.169-.621$ & .896 \\
complexity & .508 & $.398-.632$ & .926 \\
coherence & .374 & $.271-.504$ & .880 \\
tidiness & .421 & $.314-.550$ & .915 \\
\hline $\mathrm{N}$ & 48 & & \\
\hline
\end{tabular}

if two experts rate a group of scenes and one of them always assigns scores that are $\mathrm{x}$ points higher than the other (systematic error), a simple correlation coefficient would indicate complete agreement 
between them. By contrast, the ICC would accurately portray the extent of disagreement between them. The ICC is the preferred measure of interrater reliability when cases are rated in terms of some interval variable or interval-like variable, such as the Likert scales used in this study.

In this study, the 10 expert panelists independently rated each of 48 clips with respect to the nine urban design qualities, and values were compared for inter-rater reliability (see Table 3). From their ICC values, most urban design qualities demonstrate moderate inter-rater reliability among panelists $(0.6>$ ICCs $>0.4)$; the exceptions-linkage, coherence, and legibility-show fair reliability $(0.4>$ ICCS $\geq 0.2$ ). (Landis and Koch 1977) For purposes of comparison,

Cronbach's alpha is also reported for these ratings.

\section{Analyze Content of Sampled Scenes}

Our objective from the beginning of this project was to operationalize urban design qualities in objective, quantitative terms. This meant that the ratings by the expert panel,

insofar as possible, had to be explained in terms of measurable physical features of scenes. The procedural alternative to this approach, giving users either qualitative criteria or pictorial examples upon which to based urban design ratings, seemed fraught with subjectivity and imprecision.

Toward this end, all 48 video clips were analyzed for content. Physical features of each scene were "eyeballed" and then quantified with as much care and precision as the medium allowed. All told, more than 100 features were measured in this manner for each scene. The process typically required more than an hour for each video clip, and much more for the more complex scenes.

The physical features measured in this manner were derived from the urban design literature, from earlier visual assessment studies, and most importantly, from interviews with our national expert panel. As panelists were rating scenes, they were also commenting on the physical features that caused ratings to be high or low with respect to each urban design quality. Interviews, which had been taped, were reviewed to identify promising variables.
The gold standard for this activity was provided by one of the PIs and his RA, who developed detailed operational rules for measuring each physical feature. The features and operational definitions are listed in Appendix 3. The process might best be described as one of forced consensus. The PI and RA independently measured each feature, discussed differences, and finally reached agreement on a single value for each physical feature of each video clip.

\section{I nter-rater Reliability of Content Analysis}

J ust how reliably physical features can be measured is a criterion in the selection of variables for later use in operational definitions, and ultimately, for the selection urban design qualities to be operationalized. To assess inter-rater reliability of measured physical features, a random sample of video clips was assigned to three other members of the research team. The sample consisted of 12 clips in all, or four per team member. Sample size was limited by the time required to evaluate more than 100 features of each clip. 
Before they evaluated the clips in their samples, the other team members discussed the measurement of each feature with the first two team members via conference call. As these other team members evaluated each clip in their sample, they continually referred back to the operational definitions, a process that added considerably to the time required (particularly for the PI from public health, who had never done anything quite like it).

ICC and Chronbach's alpha values for physical features are presented in Table 4. For most features, there was almost perfect agreement (ICCs $\geq 0.8)$ or substantial agreement $(0.8$ $>$ ICCs $\geq 0.6$ ) among the team members. It is relatively easy to count objects and measure widths. Several features had low or even negative ICC values. Of these, features such as the number of landscape elements could probably be rated more consistently with better operational definitions. Other features, such as landscape condition, involve a high degree of judgment and might require training and/or photographic examples to achieve reasonable inter-rater reliability. Those missing values in
Table 4 had insufficient variance across the sample to compute interrater reliability statistics.

A major task in the second phase of this study will be to refine operational definitions and provide photographic examples of physical features that proved to be powerful predictors of urban design quality ratings but were not rated reliably in the first round.

Table 4: I nter-rater Reliability for Estimates of Physical Features*

\begin{tabular}{lllllllll}
\hline Variable & ICC & Alpha & Variable & ICC & Alpha & Variable & ICC & Alpha \\
$\begin{array}{l}\text { number of } \\
\text { courtyards etc. }\end{array}$ & .471 & .611 & $\begin{array}{l}\text { proportion street } \\
\text { wall - opposite } \\
\text { side }\end{array}$ & .588 & .737 & $\begin{array}{l}\text { number of small } \\
\text { planters }\end{array}$ & .968 & .982 \\
\hline arcades & --- & --- & $\begin{array}{l}\text { number of } \\
\text { enclosed sides }\end{array}$ & .389 & .640 & $\begin{array}{l}\text { landscape } \\
\text { condition }\end{array}$ & -.115 & .244 \\
\hline $\begin{array}{l}\text { number of } \\
\text { landmarks }\end{array}$ & .763 & .878 & $\begin{array}{l}\text { average building } \\
\text { setback - same } \\
\text { side }\end{array}$ & .215 & .338 & $\begin{array}{l}\text { common tree } \\
\text { spacing - same } \\
\text { side }\end{array}$ & .766 \\
\hline $\begin{array}{l}\text { number of } \\
\text { major } \\
\text { landscape } \\
\text { features }\end{array}$ & --- &.-- & $\begin{array}{l}\text { common building } \\
\text { setbacks }\end{array}$ & .814 & .897 & $\begin{array}{l}\text { common tree } \\
\text { spacing - both } \\
\text { sides }\end{array}$ & .283 \\
\hline
\end{tabular}




\begin{tabular}{|c|c|c|c|c|c|c|c|c|}
\hline Variable & ICC & Alpha & Variable & ICC & Alpha & Variable & ICC & Alpha \\
\hline $\begin{array}{l}\text { memorable } \\
\text { architecture }\end{array}$ & --- & -- & $\begin{array}{l}\text { building height - } \\
\text { same side }\end{array}$ & .741 & .864 & $\begin{array}{l}\text { number of } \\
\text { moving } \\
\text { pedestrians }\end{array}$ & .895 & .946 \\
\hline $\begin{array}{l}\text { distinctive } \\
\text { signage }\end{array}$ & 1.000 & 1.000 & $\begin{array}{l}\text { building height } \\
\text { to width ratio }\end{array}$ & .855 & .940 & $\begin{array}{l}\text { number of } \\
\text { people standing }\end{array}$ & .728 & .865 \\
\hline $\begin{array}{l}\text { number of long } \\
\text { sight lines }\end{array}$ & .585 & .714 & $\begin{array}{l}\text { building height - } \\
\text { opposite side }\end{array}$ & .939 & .966 & $\begin{array}{l}\text { number of } \\
\text { people seated }\end{array}$ & .994 & .997 \\
\hline terminated vista & .436 & .571 & $\begin{array}{l}\text { common building } \\
\text { heights }\end{array}$ & .500 & .646 & noise level & .571 & .704 \\
\hline $\begin{array}{l}\text { proportion } \\
\text { progress toward } \\
\text { intersection }\end{array}$ & .833 & .906 & $\begin{array}{l}\text { common } \\
\text { buildings masses }\end{array}$ & .690 & .833 & outdoor dining & 1.000 & 1.000 \\
\hline $\begin{array}{l}\text { proportion } \\
\text { progress toward } \\
\text { distant point }\end{array}$ & .. 718 & .860 & street width & .870 & .927 & number of tables & .916 & .954 \\
\hline $\begin{array}{l}\text { number of } \\
\text { street } \\
\text { connections }\end{array}$ & -.110 & -.296 & median width & .007 & .014 & number of seats & -.052 & -.065 \\
\hline $\begin{array}{l}\text { number of } \\
\text { buildings }\end{array}$ & .913 & .951 & sidewalk width & .693 & .807 & $\begin{array}{l}\text { number of } \\
\text { pedestrian street } \\
\text { lights }\end{array}$ & .938 & .967 \\
\hline $\begin{array}{l}\text { number of land } \\
\text { uses }\end{array}$ & .762 & .852 & $\begin{array}{l}\text { building height } \\
\text { to street width } \\
\text { ratio }\end{array}$ & .894 & .947 & $\begin{array}{l}\text { number of other } \\
\text { pieces of street } \\
\text { furniture }\end{array}$ & .933 & .969 \\
\hline $\begin{array}{l}\text { proportion } \\
\text { historic } \\
\text { buildings }\end{array}$ & .518 & .720 & $\begin{array}{l}\text { sidewalk clear } \\
\text { width }\end{array}$ & .506 & .690 & $\begin{array}{l}\text { number of misc } \\
\text { street items }\end{array}$ & .849 & .940 \\
\hline $\begin{array}{l}\text { number of } \\
\text { buildings with } \\
\text { ID }\end{array}$ & .876 & .934 & buffer width & .542 & .772 & $\begin{array}{l}\text { number of pieces } \\
\text { of public art }\end{array}$ & .529 & .748 \\
\hline
\end{tabular}




\begin{tabular}{|c|c|c|c|c|c|c|c|c|}
\hline Variable & ICC & Alpha & Variable & I CC & Alpha & Variable & ICC & Alpha \\
\hline $\begin{array}{l}\text { proportion of } \\
\text { buildings with } \\
\text { ID }\end{array}$ & .443 & .721 & $\begin{array}{l}\text { number of } \\
\text { paving materials }\end{array}$ & .641 & .861 & $\begin{array}{l}\text { number of traffic } \\
\text { signs }\end{array}$ & .876 & .946 \\
\hline $\begin{array}{l}\text { various building } \\
\text { ages }\end{array}$ & .845 & .916 & $\begin{array}{l}\text { textured } \\
\text { sidewalk surface }\end{array}$ & 1.000 & 1.000 & $\begin{array}{l}\text { number of place } \\
\text { or business signs }\end{array}$ & .761 & .865 \\
\hline $\begin{array}{l}\text { number of } \\
\text { building } \\
\text { materials }\end{array}$ & .409 & .550 & $\begin{array}{l}\text { textured street } \\
\text { surface }\end{array}$ & 1.000 & 1.000 & $\begin{array}{l}\text { number of } \\
\text { directional signs }\end{array}$ & .766 & .867 \\
\hline $\begin{array}{l}\text { number of } \\
\text { building colors }\end{array}$ & .503 & .642 & $\begin{array}{l}\text { pavement } \\
\text { condition }\end{array}$ & .627 & .771 & $\begin{array}{l}\text { number of } \\
\text { billboards }\end{array}$ & 1.000 & 1.000 \\
\hline $\begin{array}{l}\text { number of } \\
\text { accent colors }\end{array}$ & .350 & .609 & debris condition & .532 & .681 & common signage & -- & -- \\
\hline $\begin{array}{l}\text { number of } \\
\text { building } \\
\text { projections }\end{array}$ & .610 & .775 & $\begin{array}{l}\text { number of } \\
\text { parked cars }\end{array}$ & .958 & .984 & graffiti & -- & --- \\
\hline $\begin{array}{l}\text { number of } \\
\text { visible doors }\end{array}$ & .891 & .937 & $\begin{array}{l}\text { proportion } \\
\text { parked cars }\end{array}$ & .965 & .991 & $\begin{array}{l}\text { proportion sky } \\
\text { ahead }\end{array}$ & .831 & .899 \\
\hline $\begin{array}{l}\text { number of } \\
\text { recessed doors }\end{array}$ & .600 & .818 & $\begin{array}{l}\text { number of } \\
\text { moving cars }\end{array}$ & .970 & .984 & $\begin{array}{l}\text { proportion } \\
\text { buildings ahead }\end{array}$ & .550 & .690 \\
\hline $\begin{array}{l}\text { proportion of } \\
\text { recessed doors }\end{array}$ & .531 & .790 & $\begin{array}{l}\text { average speed of } \\
\text { moving cars }\end{array}$ & .862 & .919 & $\begin{array}{l}\text { proportion } \\
\text { pavement ahead }\end{array}$ & .602 & .732 \\
\hline $\begin{array}{l}\text { proportion first } \\
\text { floor facades } \\
\text { with windows }\end{array}$ & .841 & .911 & $\begin{array}{l}\text { number of } \\
\text { moving cyclists }\end{array}$ & -- & --- & $\begin{array}{l}\text { proportion cars } \\
\text { ahead }\end{array}$ & .174 & .338 \\
\hline $\begin{array}{l}\text { proportion } \\
\text { overall façades } \\
\text { with windows }\end{array}$ & .643 & .764 & $\begin{array}{l}\text { number of curb } \\
\text { extensions }\end{array}$ & .814 & .897 & $\begin{array}{l}\text { proportion street } \\
\text { furniture ahead }\end{array}$ & .837 & .906 \\
\hline
\end{tabular}




\begin{tabular}{|c|c|c|c|c|c|c|c|c|}
\hline Variable & ICC & Alpha & Variable & I CC & Alpha & Variable & ICC & Alpha \\
\hline $\begin{array}{l}\text { common } \\
\text { window } \\
\text { proportions }\end{array}$ & .845 & .916 & $\begin{array}{l}\text { number of } \\
\text { midblock } \\
\text { crossings }\end{array}$ & -- & --- & $\begin{array}{l}\text { proportion } \\
\text { landscaping } \\
\text { ahead }\end{array}$ & .911 & .949 \\
\hline $\begin{array}{l}\text { number of } \\
\text { awnings or } \\
\text { overhangs }\end{array}$ & .717 & .828 & $\begin{array}{l}\text { number of } \\
\text { midblock pass- } \\
\text { throughs }\end{array}$ & -- & --- & $\begin{array}{l}\text { proportion sky } \\
\text { across }\end{array}$ & .943 & .976 \\
\hline $\begin{array}{l}\text { proportion of } \\
\text { building height } \\
\text { interruptions }\end{array}$ & -.122 & -.064 & overhead utilities & --- & --- & $\begin{array}{l}\text { proportion } \\
\text { buildings across }\end{array}$ & .887 & .935 \\
\hline $\begin{array}{l}\text { number of non- } \\
\text { rectangular } \\
\text { silhouettes }\end{array}$ & .399 & .738 & $\begin{array}{l}\text { number of } \\
\text { landscape } \\
\text { elements }\end{array}$ & -.086 & -.019 & $\begin{array}{l}\text { proportion } \\
\text { pavement across }\end{array}$ & .700 & .808 \\
\hline $\begin{array}{l}\text { proportion non- } \\
\text { rectangular } \\
\text { silhouettes }\end{array}$ & -.040 & .251 & $\begin{array}{l}\text { landscaped } \\
\text { median }\end{array}$ & 1.000 & 1.000 & $\begin{array}{l}\text { proportion cars } \\
\text { across }\end{array}$ & .939 & .967 \\
\hline $\begin{array}{l}\text { common } \\
\text { architectural } \\
\text { styles }\end{array}$ & .431 & .675 & number of trees & .804 & .883 & $\begin{array}{l}\text { proportion street } \\
\text { furniture across }\end{array}$ & .633 & .750 \\
\hline $\begin{array}{l}\text { common } \\
\text { materials }\end{array}$ & .585 & .714 & $\begin{array}{l}\text { number of tree } \\
\text { wells }\end{array}$ & .649 & .854 & $\begin{array}{l}\text { proportion } \\
\text { landscaping } \\
\text { across }\end{array}$ & .894 & .946 \\
\hline $\begin{array}{l}\text { proportion of } \\
\text { active uses }\end{array}$ & .795 & .878 & $\begin{array}{l}\text { proportion of } \\
\text { shaded sidewalk }\end{array}$ & .922 & .956 & & & \\
\hline $\begin{array}{l}\text { proportion } \\
\text { street wall - } \\
\text { same side }\end{array}$ & .938 & .976 & $\begin{array}{l}\text { number of large } \\
\text { planters }\end{array}$ & .349 & .510 & & & \\
\hline
\end{tabular}

* For more complete variable labels and operational definitions, see Appendix 3. 


\section{Relate Urban Design Ratings to Measurable Physical Features}

Multivariate statistical methods were used to model urban design ratings in terms of measurable physical features of scenes. Models were specified based on hypothesized relationships between urban design qualities and specific physical features. These in turn were partly a matter of common sense, partly a reflection of the urban design

literature, and partly a product of the interviews with the expert panelists. To keep model building from becoming a data mining exercise, a matrix of hypothesized relationships was created and only the features plausibly linked to urban design qualities were actually tested for predictive power. Appendix 4 contains the matrix. Xs signify plausible links. Xs are bolded if physical features proved significantly related to urban design qualities.

\section{Cross-Classified Random Effects Models}

Visual assessment studies often employ multiple regression analysis to explain scene ratings in terms of objectively measured physical features. This may not be the best approach.

When an outcome varies

systematically in two dimensions, and random effects are present, the resulting data structure is best represented by a cross-classified random effects model. For an introduction to this class of models, readers are referred to Chapter 12 in Raudenbush and Bryk's Hierarchical Linear Models: Applications and Data Analysis Methods.

The outcome variable in this analysis was the urban design quality rating assigned by an individual panelist to an individual street scene. Where all 48 scenes were rated by all 10 panelists, our sample consisted of 480 ratings. For one perceptual quality, linkage, one panelist declined to provide ratings for all video clips, and the sample was slightly smaller.

Ratings varied from scene to scene due to different qualities of the street itself and its edge. Ratings also varied from viewer to viewer due to differences in judgment. Some viewers were more generous in their grading than others. Finally, ratings varied due to unique interactions between scenes and viewers. A particular scene may have evoked a particularly positive or negative reaction in a particular viewer. We viewed such unique reactions as measurement errors.

The more interesting source of variation in scores is that associated with scenes. Indeed, the purpose of this study is to identify the physical features of scenes that give rise to high or low ratings on urban design quality scales. In statistical parlance, the "scene effect" gives rise to "scene variance." While not of much interest, variation also occurs across panelists and must be accounted for Again in statistical parlance, the "viewer effect" gives rise to "viewer variance." The unique reactions of individual panelists, and the random variations in their scoring across scenes, produce "measurement error variance."

In order to bring into focus the interesting variation, that is the variation across street scenes, it helps statistically to separate the scene variance from viewer variance and measurement error variance. Doing so, we are able to eliminate viewer effects when evaluating the power of physical features to predict street scene ratings. If we had simply 
used the average ratings of scenes as the outcome variable, and the physical features of scenes as explanatory variables, the effect of scene variance might have been confounded by the effect of viewer variance.

Our analysis began by partitioning the total variance in urban design quality ratings among the three sources of variation-scenes, viewers, and measurement errors. The model consisted of two parts:

actual rating $=$ predicted rating + measurement error

where the actual rating is the sum of the predicted score for a given scene by a given viewer plus the measurement error; and

predicted rating $=$ constant + viewer effect + scene effect

where the predicted rating is just the sum of a constant plus a viewer effect and a scene effect.

These equations were estimated using HLM 5.90 software, a statistical package developed by Raudenbush, Bryk, Cheong, and Congdon (2000). For each perceptual quality, Table 5

Table 5: Variance in Ratings by Source for Each Urban Design Quality

(\% of total variance in parentheses)

\begin{tabular}{|c|c|c|c|c|}
\hline & $\begin{array}{l}\text { Scene } \\
\text { Variance }\end{array}$ & $\begin{array}{l}\text { Viewer } \\
\text { Variance }\end{array}$ & $\begin{array}{l}\text { Measurement } \\
\text { Error }\end{array}$ & Total Variance \\
\hline \multirow{2}{*}{ imageability } & 0.67 & 0.16 & 0.50 & 1.33 \\
\hline & $(50)$ & $(12)$ & (38) & \\
\hline \multirow{2}{*}{ legibility } & 0.46 & 0.17 & 0.55 & 1.18 \\
\hline & (39) & $(14)$ & $(47)$ & \\
\hline \multirow{2}{*}{ enclosure } & 0.83 & 0.10 & 0.48 & 1.41 \\
\hline & (59) & (7) & $(34)$ & \\
\hline \multirow{2}{*}{ human scale } & 0.68 & 0.11 & 0.50 & 1.29 \\
\hline & (53) & (8) & (39) & \\
\hline \multirow[b]{2}{*}{ transparency } & 0.77 & 0.13 & 0.62 & 1.52 \\
\hline & (51) & $(8)$ & $(41)$ & \\
\hline \multirow{2}{*}{ linkage } & 0.51 & 0.26 & 0.74 & 1.51 \\
\hline & $(34)$ & (17) & (39) & \\
\hline \multirow{2}{*}{ complexity } & 0.6 & 0.09 & 0.47 & 1.16 \\
\hline & $(52)$ & (8) & $(40)$ & \\
\hline \multirow{2}{*}{ coherence } & 0.45 & 0.11 & 0.62 & 1.18 \\
\hline & (38) & (9) & (53) & \\
\hline \multirow{2}{*}{ tidiness } & 0.46 & 0.17 & 0.43 & 1.06 \\
\hline & (43) & (16) & $(41)$ & \\
\hline
\end{tabular}

shows the total variance in ratings and the portions attributable to each source. The fuzzier constructs such as legibility and linkage have higher proportions attributable to viewer judgment and measurement error.

As an example, for the perceptual quality of imageability, the scene variance was 0.67 , the viewer variance was 0.16 , and the measurement error variance was
0.50 . The total variance was thus split in the following proportions: 50 percent scene variance,

12 percent viewer variance, and 38 percent measurement error variance.

For all perceptual qualities, there was more variance across scenes than across viewers. This is not unusual in visual assessment surveys.

A set of additional models was estimated in order to reduce the 
unexplained variance in perceptual quality ratings. These models included characteristics of viewers and scenes:

actual score $=$ predicted score + measurement error

exactly as above; and

predicted score $=$ constant + viewer random effect + scene random effect $+a *$ viewer $v$ ariables + b* scene variables

where the viewer random effect is the portion of the viewer effect left unexplained by viewer

characteristics, the scene random effect is the portion of the scene effect left unexplained by scene characteristics, viewer variables is the vector of relevant viewer characteristics, $a$ is the vector of associated coefficients, scene variables is the vector of relevant scene characteristics, and $b$ is the vector of associated coefficients. These variables capture the "fixed effects" of viewers and scenes on urban design ratings.

\section{Results of Statistical Analysis}

Many combinations of viewer and scene variables were tested. The only available variables characterizing viewers-urban designer or not ( 1 or 0 dummy) and new urbanist or not ( 1 or 0 dummy) - proved to have no explanatory power in most analyses. That is to say, neither variable was significant at the 0.10 probability level, except in the model for human scale, in which the variable for urban designer proved marginally

significant. Apparently urban designers and others, and new urbanists (a subset of the designers) and others, react similarly to street scenes. This is consistent with earlier visual assessment literature revealing common environmental preferences across professions.

By contrast, many of the variables characterizing scenes proved significant individually and in combination with each other. This again is consistent with the visual assessment literature. The models that reduced the unexplained variance of scores to the greatest degree, and for which all variables had the expected signs and were significant at the 0.10 level or beyond, are presented in Tables 6 through 14 . Most of the independent variables in these tables are object counts, though there are also dummy variables and proportions. See Appendix 3 for variable definitions.

In all, 37 physical features proved significant in one or more models. Six features were significant in two models: long sight lines, number of buildings with identifiers, proportion first floor façade with windows, proportion active uses, proportion street wall-same side, and number of pieces of public art. Two features were significant in three models: number of moving pedestrians and presence of outdoor dining. The models for each quality are presented and discussed below.

\section{Discussion}

\section{I mageability}

For imageability, the estimated model left the measurement error variance unchanged at 0.50 , reduced the unexplained viewer variance only slightly from 0.16 to 0.15 , but reduced the unexplained scene variance substantially, from 0.67 to 0.19 . Altogether, 72 percent of the variation across scenes, and 37 percent of the overall variation in imageability scores (including variation across viewers and measurement errors), were explained by the significant scene variables (Table 6). All of the significant scene 
variables had acceptable levels of inter-rater reliability (with intraclass correlation coefficients of 0.40 or above, except for major landscape features, which had insufficient variance across the sample to compute inter-rater reliability). The significance of the number of

pedestrians and outdoor dining points to the importance of human activity in creating imageable places. The lack of significance of landmarks, memorable architecture, and public art forces us to rethink just what makes a place memorable. Overall, the model is strong.

\section{Legibility}

For legibility, the estimated model left the measurement error variance and unexplained viewer variance unchanged (Table 5). It reduced the unexplained scene variance from 0.46 to 0.21 , accounting for only 54 percent of the scene variance and 21 percent of the total variance, the lowest percentages among the nine urban design qualities studied (Table 7 ). All of the significant scene variables had acceptable levels of inter-rater reliability, except for memorable architecture, which had insufficient variance across the sample to compute inter-rater reliability. The number of buildings
Table 6: Best-Fit I mageability Model

\begin{tabular}{llll}
\hline Variable & Coefficient & $\begin{array}{l}\text { t- } \\
\text { statistic }\end{array}$ & $\begin{array}{l}\text { p- } \\
\text { value }\end{array}$ \\
\hline constant & 2.516 & & \\
courtyards/plazas/parks (\#) & 0.393 & 3.58 & 0.001 \\
major landscape features (\#) & 0.735 & 2.00 & 0.046 \\
proportion of historic buildings & 0.948 & 4.16 & 0.000 \\
buildings with identifiers (\#) & 0.115 & 1.80 & 0.072 \\
buildings with non-rectangular silhouettes (\#) & 0.0745 & 1.95 & 0.052 \\
pedestrians (\#) & 0.0271 & 4.73 & 0.000 \\
noise level (rating) & -0.195 & -2.11 & 0.035 \\
outdoor dining (y/n) & 0.703 & 3.97 & 0.000 \\
\hline Proportion of Scene Variance Explained & 0.72 & & \\
Proportion of Total Variance Explained & 0.37 & & \\
\hline
\end{tabular}

\section{Table 7: Best-Fit Legibility Model}

\begin{tabular}{llll}
\hline Variable & Coefficient & $\begin{array}{l}\text { t- } \\
\text { statistic }\end{array}$ & p-value \\
\hline constant & 2.412 & & \\
memorable architecture $(\mathrm{y} / \mathrm{n})$ & 0.620 & 2.49 & 0.013 \\
terminated vista (y/n) & 0.722 & 3.57 & 0.001 \\
buildings with identifiers (\#) & 0.228 & 3.55 & 0.001 \\
common tree spacing and type - same side & 0.433 & 2.68 & 0.008 \\
(y/n) & & & \\
public art (\#) & 0.342 & 2.07 & 0.039 \\
place/building/business signs (\#) & 0.0537 & 2.18 & 0.030 \\
\hline Proportion of Scene Variance Explained & 0.54 & & \\
Proportion of Total Variance Explained & 0.21 & & \\
\hline
\end{tabular}


Table 8: Best-Fit Enclosure Mode

\begin{tabular}{llll}
\hline Variable & Coefficient & $\begin{array}{l}\text { t- } \\
\text { statistic }\end{array}$ & $\begin{array}{l}\text { p- } \\
\text { value }\end{array}$ \\
\hline constant & 2.570 & & 0.035 \\
long sight lines (\#) & -0.308 & -2.12 & 0.001 \\
proportion street wall - same side & 0.716 & 3.51 & 0.002 \\
proportion street wall - opposite side & 0.940 & 3.17 & 0.055 \\
proportion sky ahead & -1.418 & -1.92 & 0.021 \\
proportion sky across & -2.193 & -2.32 & \\
\hline Proportion of Scene Variance Explained & 0.72 & & \\
Proportion of Total Variance Explained & 0.43 & &
\end{tabular}

Table 9: Best-Fit Human Scale Model

\begin{tabular}{llll}
\hline Variable & Coefficient & $\begin{array}{l}\text { t- } \\
\text { statistic }\end{array}$ & $\begin{array}{l}\text { p- } \\
\text { value }\end{array}$ \\
\hline constant & 2.612 & & 0.066 \\
urban designer $(\mathrm{y} / \mathrm{n})$ & 0.382 & 1.84 & 0.000 \\
long sight lines (\#) & -0.775 & -4.97 & 0.004 \\
proportion first floor with windows & 0.916 & 2.93 & 0.077 \\
proportion active uses & 0.306 & 1.77 & 0.038 \\
building height - same side & -0.00308 & -2.08 & 0.063 \\
small planters (\#) & 0.0469 & 1.86 & 0.002 \\
miscellaneous street items (\#) & 0.0635 & 3.25 & \\
\hline Proportion of Scene Variance Explained & 0.62 & & \\
Proportion of Total Variance Explained & 0.35 & & \\
\hline
\end{tabular}

with identifiers and the number of signs have obvious conceptual connections to legibility; the significance of common tree spacing and memorable architecture is less easily explained but may be related to the ability to place the street in a larger spatial context. The set of variables in the model also has conceptual connections to imageability, suggesting that panelists may have had difficulty distinguishing between these two concepts. As noted earlier, legibility itself had a low level of inter-rater reliability. Overall, the model is weak.

\section{Enclosure}

For enclosure, the estimated model left the measurement error variance unchanged, reduced the unexplained viewer variance slightly from 0.10 to 0.09 , and reduced the unexplained scene variance from 0.83 to 0.23 . This is the largest absolute reduction in unexplained scene variance. With just five variables, the model for enclosure explains 72 percent of the scene variance and 43 percent of the total variance (Table 8 ). All of the significant variables have high levels of inter-rater reliability, with ICCs above 0.59 . The signs of the coefficients in the model are as expected, with long sight lines, proportion of the view ahead that is sky, and proportion of the view across the street that is sky detracting from the perception of enclosure. A more continuous "street wall" of building facades, on each side of the street, adds to the perception of enclosure. This model suggests that enclosure is influenced 
not just by the near side of the street but also by views ahead and across

the street. Surprisingly, the average street width, average building

setback, average building height, and relationship between the width of the street and building height were not significant. Overall, the model is strong.

\section{Human Scale}

For human scale, the estimated model left the measurement error variance unchanged, reduced the unexplained viewer variance from 0.11 to 0.08 , and reduced the unexplained scene variance from 0.68 to 0.26 . Seven variables explain 62 percent of the scene variance and 35 percent of the total variance in human scale (Table 9). All of the significant variables have ICCs of 0.59 or higher. The signs of the coefficients are as expected: the number long sight lines and building height on the same side of the street decrease the perception of human scale, while the presence of first floor windows, small planters, and street items increase the perception of human scale. Human activities are also important, specifically the proportion of street frontage with active uses. Human scale is the only quality for which characteristics of
Table 10: Best-Fit Transparency Model

\begin{tabular}{llll}
\hline Variable & Coefficient & $\begin{array}{l}\text { t- } \\
\text { statistic }\end{array}$ & $\begin{array}{l}\text { p- } \\
\text { value }\end{array}$ \\
\hline constant & 1.709 & & \\
proportion first floor with windows & 1.219 & 3.13 & 0.002 \\
proportion active uses & 0.533 & 2.96 & 0.004 \\
proportion street wall - same side & 0.666 & 2.57 & 0.011 \\
\hline Proportion of Scene Variance Explained & 0.62 & & \\
Proportion of Total Variance Explained & 0.32 & & \\
\hline
\end{tabular}

Table 11: Best-Fit Linkage Model

\begin{tabular}{llll}
\hline Variable & Coefficient & $\begin{array}{l}\text { t- } \\
\text { statistic }\end{array}$ & $\begin{array}{l}\text { p- } \\
\text { value }\end{array}$ \\
\hline constant & 2.104 & & \\
street connections to elsewhere (\#) & 0.623 & 3.31 & 0.001 \\
visible doors (\#) & 0.134 & 3.36 & 0.001 \\
proportion recessed doors & 0.613 & 3.11 & 0.002 \\
common building heights (y/n) & 0.576 & 3.52 & 0.001 \\
outdoor dining (y/n) & 0.415 & 2.21 & 0.027 \\
\hline Proportion of Scene Variance Explained & 0.61 & & \\
Proportion of Total Variance Explained & 0.21 & & \\
\hline
\end{tabular}

viewers are significant: if the viewer is an urban designer, the rating of

human scale is higher, all else equal. Overall, the model is strong.

\section{Transparency}

For transparency, the estimated model left the measurement error variance and unexplained viewer unchanged, and reduced the unexplained scene variance from 0.77 to 0.29 . Just three variables explain 62 percent of the scene variance and 32 percent of the total variance in transparency: the proportion of the first floor with windows, the proportion of active 
uses, and the proportion of street wall on the same side (Table 10). All three variables have acceptable levels of inter-rater reliability. The model suggests that being able to see into buildings and having human activity along the street frontage both contribute to the perception of transparency. Note that windows above ground-level do not increase the perception of transparency (after controlling for other variables) Overall, the model is strong.

\section{Linkage}

For linkage, the estimated model left the measurement error variance and unexplained viewer unchanged, and reduced the unexplained scene variance from 0.51 to 0.20 . The model for linkage, with five variables, explains 61 percent of scene variance but only 21 percent of total variance (Table 11). Linkage has the highest view variance and measurement error of the nine urban design features, and is tied with legibility for the smallest percentage of total variance explained. These statistics indicate lack of clarity in the concept of linkage. Four of the five variables in the model had acceptable levels of inter-rater reliability; the number of street connections to other places was the notable exception. The
Table 12: Best-Fit Complexity Model

\begin{tabular}{llll}
\hline Variable & Coefficient & $\begin{array}{l}\text { t- } \\
\text { statistic }\end{array}$ & $\begin{array}{l}\text { p- } \\
\text { value }\end{array}$ \\
\hline constant & 1.453 & & 0.016 \\
buildings (\#) & 0.0458 & 2.42 & 0.007 \\
dominant building colors (\#) & 0.225 & 2.74 & 0.027 \\
accent colors (\#) & 0.115 & 5.96 & 0.000 \\
pedestrians (\#) & 0.0311 & 2.30 & 0.022 \\
outdoor dining (y/n) & 0.418 & 1.96 & 0.051 \\
public art (\#) & 0.286 & & \\
\hline Proportion of Scene Variance Explained & 0.73 & & \\
Proportion of Total Variance Explained & 0.38 & & \\
\hline
\end{tabular}

significance of recessed doors, outdoor dining, and common building heights on opposite sides of the street suggests the importance of psychological as well as physical connections between buildings, sidewalks, and streets. Overall, the model is weak.

\section{Complexity}

For complexity, the estimated model left the measurement error variance and viewer variance unchanged, while reducing unexplained scene variance from 0.67 to 0.19 . Six variables explain 73 percent of scene variance and 38 percent of total variance for complexity (Table 12). Except for the number of accent colors, all variables have acceptable levels of inter-rater reliability, and the signs on the coefficients are in the expected direction. The significance of pedestrians and outdoor dining suggests that human activity may contribute as much to the perception of complexity as do physical elements. The lack of significance of several other variables is notable: number of building materials, number of building projections, textured sidewalk surfaces, number of streets lights and other kinds of street furniture, among others. Overall, the model is strong.

\section{Coherence}

For coherence, the estimated model left the measurement error variance and unexplained viewer variance 
unchanged, and reduced the unexplained scene variance from 0.45 to 0.15 . Only four variables were significant in the model for coherence (Table 13). These variables explained 67 percent of the scene variance but only 25 percent of the total variance. All variables except common tree spacing have ICCs over 0.85, indicating a high degree of inter-rater reliability. Two of the variables have strong conceptual connections to coherence: common window proportions and common tree spacing and type on both sides of the street. Connections to the other two variables are less obvious. Pedestrian scale street lights are always of uniform style and size and unify scenes visually to a surprising degree. Pedestrians become a dominant and relatively uniform element as their numbers increase. Other conceptually important variables are missing from the model, including common architectural styles and common building masses. Overall, this model is weak.

\section{Tidiness}

For tidiness, the estimated model left the measurement error variance and unexplained viewer variance unchanged, while reducing the

Table 13: Best-Fit Coherence Mode

\begin{tabular}{|c|c|c|c|}
\hline Variable & Coefficient & $\begin{array}{l}\text { t- } \\
\text { statistic }\end{array}$ & $\begin{array}{l}\text { p- } \\
\text { value }\end{array}$ \\
\hline Constant & 2.495 & & \\
\hline common window proportions $(y / n)$ & 0.979 & 6.18 & 0.000 \\
\hline $\begin{array}{l}\text { common tree spacing and type - both } \\
\text { sides }(y / n)\end{array}$ & 0.356 & 2.41 & 0.016 \\
\hline pedestrians (\#) & 0.0217 & 4.29 & 0.000 \\
\hline pedestrian scale street lights (\#) & 0.0566 & 1.81 & 0.070 \\
\hline Proportion of Scene Variance Explained & 0.67 & & \\
\hline Proportion of Total Variance Explained & 0.25 & & \\
\hline \multicolumn{4}{|l|}{ Table 14: Best-Fit Tidiness Model } \\
\hline Variable & Coefficient & $\begin{array}{l}\text { t- } \\
\text { statistic }\end{array}$ & $\begin{array}{l}\text { p- } \\
\text { value }\end{array}$ \\
\hline pavement condition (rating) & 0.197 & 3.31 & 0.001 \\
\hline debris condition (rating) & 0.272 & 3.84 & 0.000 \\
\hline overhead utilities $(y / n)$ & -0.638 & -2.34 & 0.020 \\
\hline landscape condition (rating) & 0.230 & 4.29 & 0.000 \\
\hline Proportion of Scene Variance Explained & 0.70 & & \\
\hline Proportion of Total Variance Explained & 0.30 & & \\
\hline
\end{tabular}

unexplained scene variance from 0.46 to 0.14 . The model for tidiness explained 70 percent of scene variance and 30 percent of total variance with just four variables (Table 14). Two of these variables, ratings of pavement condition and debris condition, had acceptable inter-rater reliability; the rating of landscape condition did not, and the variability in overhead utilities was not large enough to compute interrater reliability. The coefficients of all explanatory variables have the expected signs, and the variables are those with the strongest conceptual connections to tidiness. Overall, the model is strong, although inter-rater reliability for landscape condition is a concern. 


\section{Select Which Qualities to Define Operationally}

In Section 8, we established criteria for deciding which urban design qualities to operationalize. They were: significant relationship of the quality to overall walkability ( $\mathrm{p} \leq$ 0.05); ability to measure the quality with at least moderate inter-rater reliability $(I C C \geq 0.4)$; ability to explain overall variations in the quality to a moderate degree with measurable scene variables

(explained portion $\geq 0.3$ ); ability to explain scene-specific variations in the quality to a substantial degree with measurable scene variables (explained portion $\geq 0.6$ ); and ability to measure these same variables with at least moderate inter-rater reliability $(I C C \geq 0.4)$. A

performance summary for each quality with respect to each criterion is presented in Table 15

According to these criteria, the qualities of imageability, enclosure, human scale, and transparency have great potential for operationalization. They meet all five criteria. The qualities of legibility, linkage, and coherence have very little potential for operationalization, each meeting only one of five criteria. They will be
Table 15: Performance of Urban Design Qualities Relative to Selection Criteria

\begin{tabular}{|c|c|c|c|c|c|}
\hline & $\begin{array}{l}\text { Relationship to } \\
\text { Walkability in } \\
\text { Best-Fit Model } \\
\text { (p-value) }\end{array}$ & $\begin{array}{l}\text { I nter- } \\
\text { rater } \\
\text { reliability } \\
\text { (ICC) }\end{array}$ & $\begin{array}{l}\text { Portion of } \\
\text { Scene } \\
\text { Variance/ Total } \\
\text { Variance } \\
\text { Explained by } \\
\text { Best-Fit } \\
\text { Models } \\
\end{array}$ & $\begin{array}{l}\text { Inter-rater } \\
\text { Reliability of } \\
\text { Significant } \\
\text { Variables } \\
\text { ( number with } \\
\text { ICC }>0.4 \text { ) }\end{array}$ & $\begin{array}{l}\text { Criteria } \\
\text { Met }\end{array}$ \\
\hline Imageability & 0.000 & 0.494 & $0.72 / 0.37$ & $\begin{array}{l}7 \text { of } 7 \\
(1 \text { missing) }\end{array}$ & 5 of 5 \\
\hline Legibility & -- & 0.380 & $0.54 / 0.21$ & $\begin{array}{l}5 \text { of } 5 \\
\text { ( } 1 \text { missing) }\end{array}$ & 1 of 5 \\
\hline Enclosure & 0.016 & 0.584 & $0.72 / 0.43$ & 5 of 5 & 5 of 5 \\
\hline Human scale & 0.000 & 0.508 & $0.62 / 0.35$ & 7 of 7 & 5 of 5 \\
\hline Transparency & 0.023 & 0.499 & $0.62 / 0.32$ & 3 of 3 & 5 of 5 \\
\hline Linkage & --- & 0.344 & $0.61 / 0.21$ & 4 of 5 & 1 of 5 \\
\hline Complexity & -- & 0.508 & $0.73 / 0.38$ & 5 of 6 & 3 of 5 \\
\hline Coherence & -- & 0.374 & $0.67 / 0.25$ & 3 of 4 & 1 of 5 \\
\hline Tidiness & 0.117 & 0.421 & $0.70 / 0.30$ & $\begin{array}{l}2 \text { of } 3 \\
\text { ( } 1 \text { missing) }\end{array}$ & 3 of 5 \\
\hline
\end{tabular}

given no further consideration. The qualities of complexity and tidiness

fall somewhere between the extremes, meeting three of five criteria; tidiness comes close to meeting a fourth. The research team has thus decided to include these two urban design qualities, along with the first four qualities that meet all criteria, in the field survey instrument. 


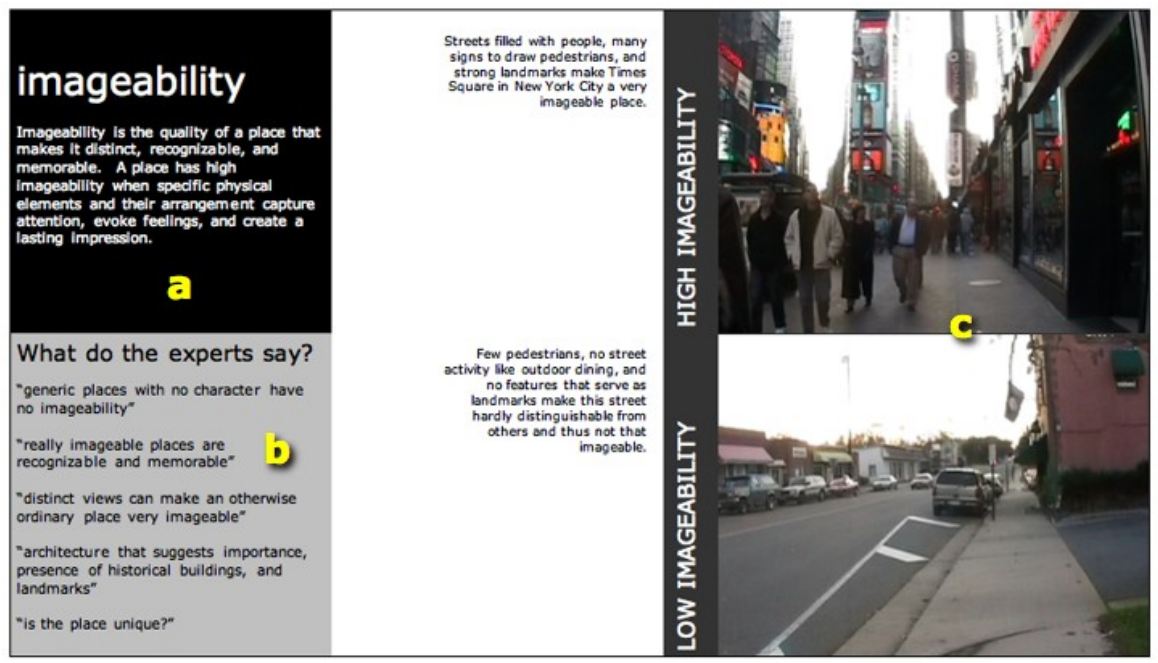

Figure 6: I ntroduction to One Urban Design Quality, I mageability

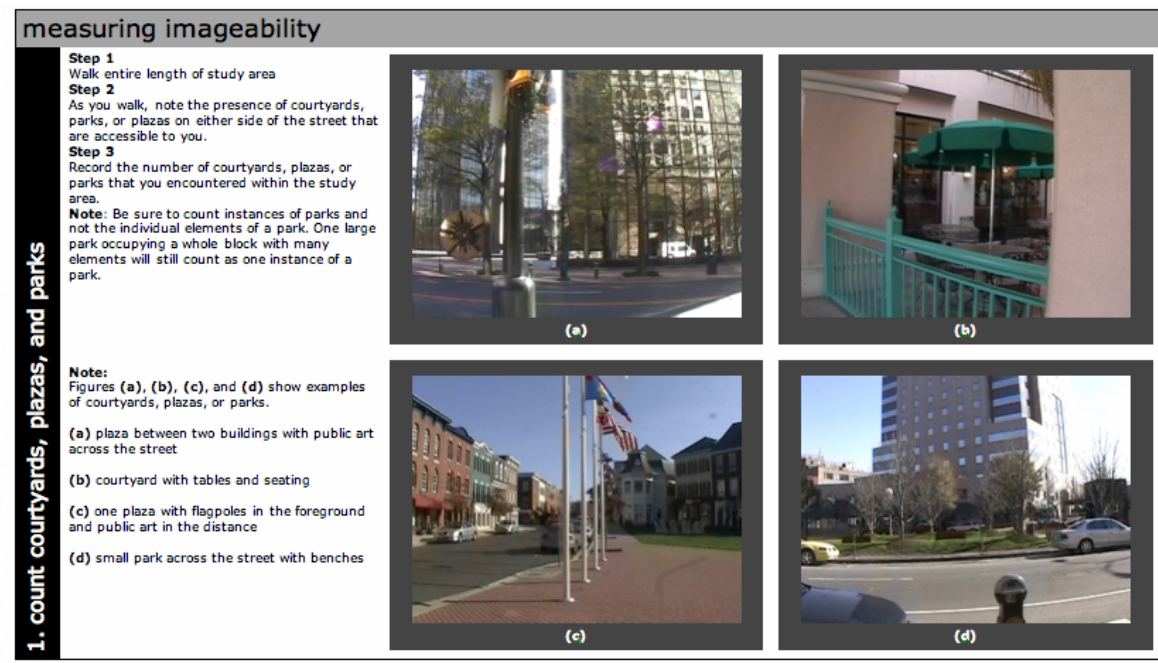

Figure 7: I nstructions for Measuring a Physical Feature Related to I mageability

The instrument showed users how to measure physical features related to each of these qualities and how to convert these measurements into urban design quality scores based on the statistical models described in Section 11. Each urban design quality in the manual was presented with a set of instructions (see Figure 6 ). All of the instructions followed the same format:

The first page of instructions introduced users to the urban design quality with:

human scale transparency complexity

tidiness quality was provided. This definition was based on the urban design literature and was refined with the help of the expert panel of urban designers and top professionals from related fields.

(b) Expert panel comments: Our research on urban design qualities included extensive interviews with and surveys of the expert panel. We reported a sample of what they had to say about each quality.

(c) Photographic examples: Two contrasting photos were shown to illustrate extreme examples of each urban design quality, as judged by (a) Qualitative definition: A short and concise definition of the urban design 
the expert panel. Short descriptions were also provided pointing out the features that made each scene either high or low with respect to the quality.

The next few pages of instructions showed users how to measure the urban design quality. Measuring urban design qualities involves visiting streets and being able to identify and count certain street features (see Figure 7). Users also need to make educated estimates of other features. Detailed illustrations were provided for each measurement needed to arrive at a value of the urban design quality.

The last page of the manual provided a scoring sheet that can be used on the field to record measurements and calculate urban design quality scores for the street segment in question. The scoring sheet summarized field measurements and provided a multiplier to be applied to each relevant physical feature in order to compute an overall urban design quality score (see Figure 8).

\section{Test and Refine the Draft I nstrument}

With the draft instrument available, principal investigators went into the

\begin{tabular}{|c|c|c|c|}
\hline \multirow{2}{*}{$\begin{array}{l}\text { measuring urban design qualities scoring sheet } \\
\text { street }\end{array}$} & \multicolumn{3}{|l|}{ auditor } \\
\hline & \multicolumn{3}{|l|}{ date \& time } \\
\hline step & $\begin{array}{l}\text { recorded } \\
\text { value }\end{array}$ & multiplier & $\begin{array}{l}\text { (multiplier) } x \\
\text { (recorded value) }\end{array}$ \\
\hline \multicolumn{4}{|l|}{ imageability } \\
\hline 1. number of courtyards, plazas, and parks (both sides, within study area) & & 0.41 & \\
\hline 2. number of major landscape features (both sides, beyond study area) & & 0.72 & \\
\hline 3. progortion historic building frontage (both sides, within study area) & & 0.97 & \\
\hline 4. number of buildings with identifiers (both sides, within study area) & & 0.11 & \\
\hline 5. number of buildings with non-rectangular shapes (both sides, within study area) & & 0.08 & \\
\hline 6. presence of outdoor dining (your side, within study area) & & 0.64 & \\
\hline 7. number of people (your side, within study area) & & 0.02 & \\
\hline 8. noise level (both sides, within study area) & & -0.18 & \\
\hline & \multicolumn{2}{|c|}{$\begin{array}{r}\text { add constant } \\
\text { imageablity score }\end{array}$} & +2.44 \\
\hline \multicolumn{4}{|l|}{ enclosure } \\
\hline 1. number of long sight lines (both sides, beyond study area) & & -0.31 & \\
\hline 2a. proportion street wall (your side, beyond study area) & & 0.72 & \\
\hline 2b. proportion street wall (opposite side, beyond study area) & & 0.94 & \\
\hline
\end{tabular}

\section{Figure 8: Portion of the Urban Design Qualities Scoring Sheet}

field with graduate students to test measurement protocols. Scenes that were part of the original visual assessment survey were used to assess whether measurements of physical features in the field were consistent with measurements in the lab using video clips. We were attempting to validate the use of video clips in our earlier urban design quality analyses. We were also seeing how the protocol used to shoot clips would translate into a procedure for field measurements.

In the field, we measured all physical features that proved significant contributors to the six remaining urban design qualities. We did this for a sample of 16 street scenes from our original set of 48 scenes.

Resulting field measurements were compared to our "gold standard" estimates based on video clips. Field observations and video clips were compared for: (1) inter-rater reliability of individual measurements; (2) inter-rater reliability of urban design quality scores based on the individual measurements: (3) rank-order correlations of individual measurements (assuming that 
relative ranking of scenes might be comparable even if absolute values differ between field observations and video clips); and (4) rank-order correlations of urban design quality scores (assuming again that relative rankings might be comparable even if absolute values differ). Table 16 summarizes our results.

What we found were major discrepancies between measurements in the field and the lab for certain physical features, and hence significant discrepancies for the urban design qualities to which they contribute in our scoring formulas. Discrepancies were significant for the following qualities and contributing features (the latter in parentheses):

- imageability (number of buildings with identifiers and noise level)

- enclosure (number of long sight lines and proportion sky across the street)

- human scale (number of long sight lines)

- complexity (number of primary building colors and number of accent colors)

- tidiness (debris condition and landscape condition)

\section{Table 16: I nitial Field Manual Test Results}

\begin{tabular}{|c|c|c|c|c|}
\hline & \multirow[b]{2}{*}{ Alpha } & \multirow[b]{2}{*}{ ICC } & \multicolumn{2}{|c|}{ Spearman } \\
\hline & & & & $\mathbf{p}$ \\
\hline I mageability & 0.682 & 0.111 & 0.49 & 0.055 \\
\hline 1. number of courtyards, plazas, and parks (both sides, within study & 0.747 & 0.557 & 0.58 & 0.018 \\
\hline 2. number of major landscape features (both sides, beyond study area) & \multicolumn{4}{|c|}{ not enough variance } \\
\hline 3. proportion historic building frontage (both sides, within study area) & 0.808 & 0.558 & 0.68 & 0.004 \\
\hline 4. number of buildings with identifiers (both sides, within study area) & 0.13 & -0.404 & 0.24 & 0.379 \\
\hline 5. number of buildings with non-rectangular shapes (both sides, within & 0.876 & 0.775 & 0.81 & 0.000 \\
\hline 6. presence of outdoor dining (your side, within study area) & 0.921 & 0.854 & 0.86 & 0.000 \\
\hline 7. number of pedestrians (your side, within study area) & 0.782 & 0.646 & 0.51 & 0.044 \\
\hline 8. noise level (both sides, within study area) & 0.454 & 0.284 & 0.3 & 0.263 \\
\hline Enclosure & 0.73 & 0.175 & 0.41 & 0.111 \\
\hline 1. number of long sight lines (both sides, beyond study area) & 0.457 & 0.129 & 0.34 & 0.194 \\
\hline 2a. proportion street wall (your side, beyond study area) & 0.837 & 0.731 & 0.83 & 0.000 \\
\hline 2b. proportion street wall (opposite side, beyond study area) & 0.466 & 0.298 & 0.51 & 0.042 \\
\hline 3a. proportion sky (ahead, beyond study area) & 0.634 & 0.361 & 0.56 & 0.026 \\
\hline 3b. proportion sky (across, beyond study area) & 0.605 & 0.197 & 0.33 & 0.206 \\
\hline Human Scale & 0.662 & 0.515 & 0.78 & 0.000 \\
\hline 1. number of long sight lines (both sides, beyond study area) & 0.457 & 0.129 & 0.34 & 0.194 \\
\hline 2. proportion windows at street level (your side, within study area) & 0.818 & 0.559 & 0.69 & 0.003 \\
\hline 3. proportion active uses (your side, within study area) & 0.797 & 0.678 & 0.64 & 0.007 \\
\hline 4. average building heights (your side, within study area) & 0.864 & 0.767 & 0.77 & 0.000 \\
\hline 5. number of small planters (your side, within study area) & 0.796 & 0.594 & 0.61 & 0.012 \\
\hline 6. number of miscellaneous street items (your side, within study area) & 0.489 & 0.22 & 0.64 & 0.008 \\
\hline Transparency & 0.891 & 0.785 & 0.9 & 0.000 \\
\hline 1. proportion windows at street level (your side, within study area) & 0.82 & 0.568 & 0.68 & 0.004 \\
\hline 2. proportion street wall (your side, beyond study area) & 0.833 & 0.727 & 0.82 & 0.000 \\
\hline 3. proportion active uses (your side, within study area) & 0.797 & 0.678 & 0.64 & 0.007 \\
\hline Complexity & 0.57 & -0.199 & 0.48 & 0.06 \\
\hline 1. number of buildings (both sides, beyond study area) & 0.869 & 0.342 & 0.7 & 0.003 \\
\hline 2a. number of primary building colors (both sides, beyond study area) & 0.143 & -0.315 & 0.07 & 0.811 \\
\hline 2b. number of accent colors (both sides, beyond study area) & 0.413 & -0.02 & 0.41 & 0.117 \\
\hline 3. presence of outdoor dining (your side, within study area) & 0.842 & 0.692 & 0.77 & 0.000 \\
\hline 4. number of pieces of public art (both sdies, within study area) & \multicolumn{4}{|c|}{ not enough variance } \\
\hline 5. number of pedestrians (your side, within study area) & 0.858 & 0.675 & 0.83 & 0.000 \\
\hline Tidiness & 0.058 & -0.167 & -0.01 & 0.959 \\
\hline 1. pavement condition (your side, within study area) & 0.735 & 0.215 & 0.59 & 0.017 \\
\hline 2. debris condition (your side, within study area) & -0.203 & -0.105 & -0.08 & 0.758 \\
\hline 3. overhead utilities (both sides, within study area) & \multicolumn{4}{|c|}{ not enough variance } \\
\hline 4. landscape condition (your side, within study area) & 0.391 & 0.114 & 0.28 & 0.293 \\
\hline
\end{tabular}


The time between the filming of video clips and the field validation accounted for some of the discrepancies. More than a year had passed, and validations often occurred at a different time of day, day of the week, and season of the year. Figure 9 compares one scene at the time of original filming to the same scene at the time of field validation. Occurring after a long winter, the validation process found many streets stark, de-populated, and in need of maintenance.

Other discrepancies arose from the greater distance observers could travel in about the same time when simply walking rather than shooting video clips. Count totals tended to be higher in the field than the lab because the field survey protocol took observers farther down the block. For some scenes, counts were much higher. For others, they were only marginally so.

Still other discrepancies were inherent in the medium used in the lab, that is, in the video clips themselves. Shadows, glare, and panning limited what could be seen in the clips, particularly on the opposite side of the street and ahead in the distance. We could not read signs across the street. We could not distinguish different shades of colors. We could not see buildings in the distance.

To deal with discrepancies, we had four options: (1) ignore them on the assumption that the relationships between urban design qualities and physical features are as estimated from the clips, even if measurements differ; (2) refine field measurement protocols to more close approximate measurements based on clips;

(3) drop physical features that could not be measured consistently in the field, and re-estimate the formulas without these features; or (4) drop urban design qualities that could not be estimated consistently due to inconsistent measures of component physical features.

Option (2) was preferred where feasible. For certain features, changes in measurement protocols were implemented through changes in the field survey manual. Number of building colors, for example, could be estimated more consistently by instructing users to count only the number of basic colors, not shadings. Noise levels could be estimated more consistently by instructing users to

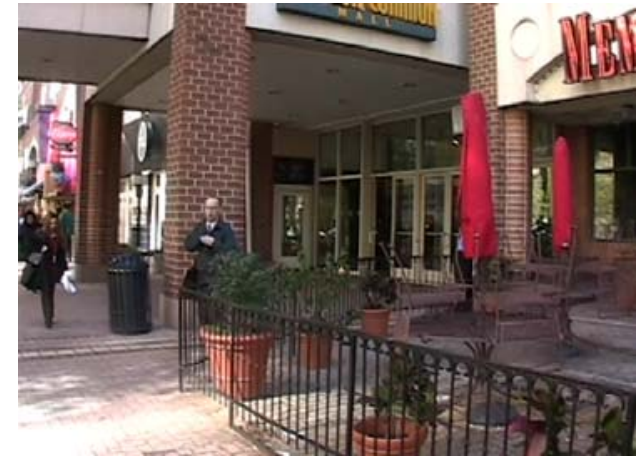

(a)

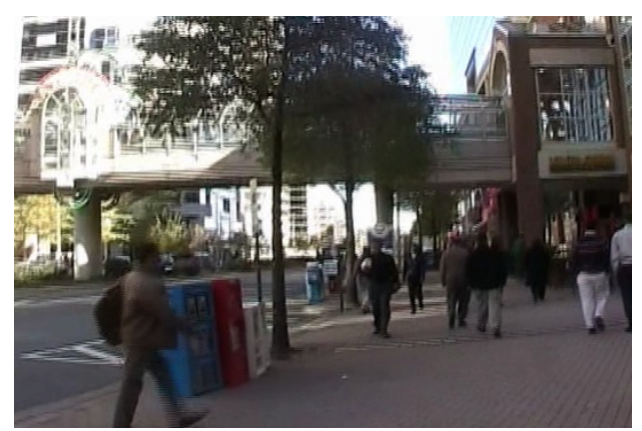

(b)

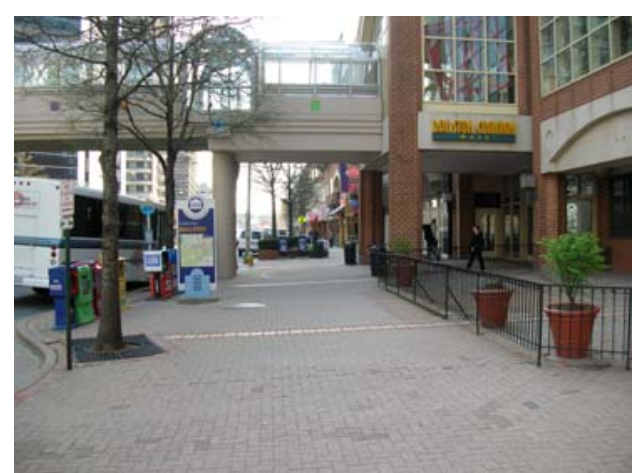

(c)

Figure 9: Comparison of One Scene at Time of Original Filming ( $a$ and $b$ ) and at Time of Field Validation (c) 
average noise levels over several passes of study area.

For two features, field experience taught us to combine elements treated separately in our original analyses. The distinction between people walking, standing, and sitting struck us artificial as we walked the same stretch of street several times. Walkers became standers etc. The distinction among the different categories of street furniture and miscellaneous street items was difficult to keep straight. Parking meters and trash cans were in one category, hydrants and ATMs in another. Tables, seating, and street lights were in a third, fourth, and fifth categories.

So we decided to combine categories and test the resulting variables in our urban design quality models. The combined variable "people" within a scene was substituted for "moving pedestrians" in the models of imageability and complexity. It had a slightly higher significance level in the imageability model, without greatly affecting the relationship of other variables to imageability ratings. It did not perform as well as moving pedestrians in the complexity model.
The combined variable "all street furniture and other street items" was substituted for "miscellaneous street items" in the model of human scale.

This variable is the sum of number of tables, number of seats, number of pedestrian-scale street lights, number of pieces of other street furniture, and number of miscellaneous street items. It improved the overall explanatory power of the human scale model, and caused one of the variables that had been significant-proportion of active uses along the street-to no longer be so. The proportion of active uses is highly correlated with the new combined "all street furniture and other street items" variable. The new combined variable was also tested in the complexity model and proved insignificant.

For one urban design quality-

tidiness-field and lab estimates were inconsistent even as measured by the Spearman rank-order correlation coefficient. Two of the component physical features, debris condition and landscape condition, contributed to the low inter-rater reliability. These features are highly variable over time and more subjective than most others in our urban design formulas. Exercising option (3), and dropping them from the tidiness formula, would have left only two significant physical features upon which to base tidiness scores. Given the weak relationship between tidiness and walkability ratings by our expert panel, we decided to drop tidiness from the final version of the field survey manual.

\section{Train Lay Observers in the Classroom}

With the final field survey instrument in hand, lay observers were given classroom training in its use. The classroom training took three hours. The lay observers were students from UC Davis. Eight students participated in the training. A sub-sample of video clips from the original visual assessment survey were used as the training medium in the classroom, where students could compare their measurements of physical features with the gold standard established by the research team

The protocol for the classroom training was as follows:

Items needed for classroom training:

- laptop for trainer

- digital projector

- 32-clip DVD (comes with training package) 
- scoring sheets with "gold standard" measurements for test clips (come with training package)

- field survey manuals for participants

Step 1. Review Field Survey Manual Trainees were given copies of the field survey manual and were introduced to its contents. For each urban design quality, the component physical features were reviewed, and the measurement protocols were described. Trainees were shown scoring sheets at the end of the manual. They were encouraged to ask questions.

\section{Step 2. Review Gold Standard} Measurements for Test Clips A video clip (clip \#14 on the DVD) from the original expert panel visual assessment survey was shown to trainees via DVD and digital projector. The first scoring sheet is filled out with the research team's "gold standard" measurements. For each physical feature on the scoring sheet, the gold standard measurement was reviewed as the clip was played. The clip was replayed as many times as required to review all physical features on the scoring sheet. The gold standard measurements were not presented as hard and fast, only as values arrived at through a careful process.

Step 3. Make Independent Measurements for Additional Test $\underline{\text { Clips }}$

For another video clip (clip \#27), trainees made measurements on their own, filling out a blank scoring sheet as they went along. The clip was replayed as many times as required for them to complete the task. When all trainees were done, the trainer read, and trainees recorded, the gold standard measurements next to trainees' own measurements. The clip was then reviewed to reconcile differences in measurements. Again, gold standard measurements were not presented as indisputable. Much time was spent discussing differences. This process could be repeated with additional clips ("gold standard scores" have been provided for clip \#'s 31, 25, 16, 12,24 , and 29) until all trainees, in a show of hands, express confidence in their ability to measure physical features of scenes consistently.

\section{Field Test the Survey Instrument with Lay Observers}

After the UC Davis students were trained in the classroom, they were sent to the field to complete observations for selected street segments. Ten segments in downtown Davis, CA and six segments in downtown Sacramento, CA were used for this field test. These segments were chosen to achieve as much variation as possible in the measured qualities. Two students were assigned to each segment to enable an analysis of inter-rater reliability. A total of 32 observations were thus completed. Raters were debriefed after completing their observations and provided suggestions for clarifying instructions in the field manual.

ICC and Chronbach's alpha values for physical features and for urban design quality scores are presented in Table 17. For half of the features, there was almost perfect agreement (ICCs $\geq 0.8)$ or substantial agreement $(0.8>$ ICCs $\geq 0.6)$ between the raters. For four more features, there was good agreement $(0.6>$ ICCs $\geq 0.4)$. 


\section{Table 17: Field Test Results}

\section{I mageability}

1. number of courtyards, plazas, and parks (both sides, within study

2. number of major landscape features (both sides, beyond study area)

927

863

$\begin{array}{ll}.845 & .584 \\ \mathrm{n} / \mathrm{a} & \mathrm{n} / \mathrm{a}\end{array}$

3. proportion historic building frontage (both sides, within study area)

864

750

4. number of buildings with identifiers (both sides, within study area)

5. number of buildings with non-rectangular shapes (both sides, within

.875

6. presence of outdoor dining (your side, within study area)

7. number of pedestrians (your side, within study area)

8. noise level (both sides, within study area)

\section{Enclosure}

1. number of long sight lines (both sides, beyond study area)

2a. proportion street wall (your side, beyond study area)

2 b. proportion street wall (opposite side, beyond study area)

3a. proportion sky (ahead, beyond study area)

3b. proportion sky (across, beyond study area)

\section{Human Scale}

1. number of long sight lines (both sides, beyond study area)

2. proportion windows at street level (your side, within study area)

3. proportion active uses (your side, within study area)

4. average building heights (your side, within study area)

5. number of small planters (your side, within study area)

6. number of miscellaneous street items (your side, within study area)

\section{Transparency}

1. proportion windows at street level (your side, within study area)

2. proportion street wall (your side, beyond study area)

3. proportion active uses (your side, within study area)

Complexity

1. number of buildings (both sides, beyond study area)

2a. number of primary building colors (both sides, beyond study area)

2b. number of accent colors (both sides, beyond study area)

3. presence of outdoor dining (your side, within study area)

4. number of pieces of public art (both sides, within study area)

5. number of pedestrians (your side, within study area)
For seven features, agreement was fair or poor for a variety of possible reasons:

- Long sight lines: There was very little variation in the measurements for this feature.

Only four values are possible, and none of the test segments had more than 2 long sight lines. Still, the disagreement between raters was often large: on five segments, one rater indicated 0 sight lines, while the other rater indicated 2 sight lines. As a result, we modified the instructional language in the field manual.

- Street wall: The poor results for street wall were influenced by two segments in particular. On one segment, a five-story parking garage abutted the sidewalk, although the ground floor was set back several feet. On another segment, several detached buildings were set back several feet from the sidewalk. In both cases, the raters made different decisions about whether to count the buildings as a part of the street wall. With these two segments removed, the ICC for 
this feature is 0.605 . The field manual was edited to more clearly specify which buildings contribute to the street wall.

- Sky ahead and sky across: Raters found these measurements difficult to estimate in the field, although they were relatively easy to estimate from the video clips. Differences between the raters stemmed from differences in the choice of exact location from which they estimated proportion sky and difficulty in judging the extent of their field of vision. The field manual now suggests the use of a cardboard frame to ensure consistency.

- Active uses: The poor results for this feature are related to the poor results for street walls. Because raters made different judgments about which buildings fronted on the street, they came up with different proportions of buildings with active uses. When the two problematic segments were excluded from the analysis, the ICC increased to 0.562 .

- Number of buildings: The results for this feature were fair. Large differences for one segment can be explained by differences in the interpretation of which buildings were visible enough to be counted. With the problematic segment excluded from the analysis, the ICC increased to 0.685 .

- Basic colors and accent colors: The poor results for these features can be partly explained by the low variation. However the measurements for these features were inconsistent for most segments. Raters differed in their judgment of whether two colors were sufficiently different to count as two colors; tans, grays, and other neutrals seemed particularly challenging.

Among the urban design qualities, I mageability had the highest reliability, closely followed by Complexity and Transparency. The reliability for Human Scale was lower but still good. However, the reliability for Enclosure was poor, given the poor reliability for sight lines, sky ahead, and sky across. Improvements in reliability for these features would improve the reliability for Enclosure.

Based on these results and the comments and suggestions of the raters, several refinements were made to the field manual. Although the final version of the field manual was not retested for inter-rater reliability, we believe that the refinements will improve reliability. In addition, a longer classroom training session that focuses on the problematic features should help to increase inter-rater reliability.

\section{Finalize the I nstrument}

The instrument was finalized based on the classroom and field experience. The field instrument, training materials, and final report are now available on-line at www.activelivingresearch.org. The field instrument includes: qualitative definitions of urban design qualities; explanations and photographic illustrations of physical features relating to urban design qualities; procedures for field observation and data collection; and scoring procedures for translating objectively measured physical features into urban design quality scores. A DVD of video clips and sample scoring sheets are available as part of the training package. 


\section{Appendix 1: Biosketches of Expert Panel Members}

Victor Dover is a principal of Dover, Kohl \& Partners, founded in 1987 and based in South Miami, Florida. Mr. Dover earned his Bachelor of Architecture degree from Virginia Tech and his Master's Degree in Town \& Suburb Design from the University of Miami. He has been certified by the American Institute of Certified Planners and is a charter member of the Congress for the New Urbanism. Mr. Dover and his partner Mr. Kohl have been recognized by Architecture magazine as being "among the country's best architects and urban designers."

Geoffrey Ferrell established his own urban design firm in 1992. Before that, Mr. Ferrell worked as a

Designer/Code Writer for DuanyPlater-Zyberk Architects and Town Planners in Miami and as the Director of Urban Design for the Treasure Coast Regional Planning Council in Florida. Mr. Ferrell holds a Master of Architecture degree with a Certificate in American Urbanism from the University of Virginia, a Bachelor of Architecture from Oregon School of Design, and a Bachelor of Science in Public Policy from Willamette
University. Mr. Ferrell is a Charter Member of the Congress for the New Urbanism. His work is featured in the book The New Urbanism by Peter Katz.

Mark Francis is Professor of Landscape Architecture at the University of California, Davis where he founded and directed the Center for Design Research. Trained in landscape architecture and urban design at Berkeley and Harvard, his work is concerned with the design and theory of urban places. He is Associate Editor of the J ournal of Architectural and Planning Research and serves on the editorial boards of several journals including Landscape J ournal, Environment and Behavior, J ournal of Planning Literature and Children and Youth Environments. His most recent books are Urban Open Space and Village Homes (Island Press 2003).

Michael Kwartler is the founding director of the Environmental Simulation Center, a non-profit research laboratory created to develop innovative applications of information technology for community planning, design and decision-making. He conceived and directed the design and development of CommunityViz ${ }^{\mathrm{TM}}$, the first GIS based planning decision support software to fully integrate virtual reality with scenario design, impact analysis and policy simulation. He was made a Fellow of the American Institute of Architects in 1990 for his achievements in urban design and performance zoning.

Robert Lane is the Director of the Regional Design Program and the Healthy Communities I nitiative at the Regional Planning Association of New York and New Jersey. Mr. Lane is the author of numerous urban design studies and town plans that emphasize compact mixed-use development, alternative forms of mobility and other dimensions of active living community design. Robert Lane is also the co-principal investigator on several "natural experiments" including measuring the impacts on activity levels of a new greenway in Stamford (Connecticut) and of new transit services in New Jersey.

Anne Vernez Moudon is Professor of Architecture, Landscape Architecture, and Urban Design and Planning at the University of Washington, Seattle. She is President of the International Seminar on 
Urban Morphology (ISUF), a Faculty Associate at the Lincoln Institute of Land Policy, a Fellow of the Urban Land Institute, a National Advisor to the Robert Wood Johnson

Foundation, and an active participant in The Mayors' Institute on City Design. Dr. Moudon holds a B.Arch. from the University of California, Berkeley, and a Doctor ès Science from the Ecole Polytechnique Fédérale of Lausanne, Switzerland. Her published works include Built for Change: Neighborhood Architecture in San Francisco (MIT Press 1986), Public Streets for Public Use

(Columbia University Press (1991), and Monitoring Land Supply with Geographic Information Systems (with M. Hubner, John Wiley \& Sons, 2000).

Anton Nelessen is founder and president of the award winning firm, A. Nelessen Associates He served as consultant on seven of the 10 Smart Growth awards given by the State of New Jersey. Mr. Nelessen has been a professor at Harvard University and at the Rutgers University Department of Urban Planning and Policy

Development since 1974. His trademarked Visual Preference Survey has been used to generate Comprehensive Plans, Master Plans and specific Urban Design Plans all over the United States. Mr. Nelessen is a charter member of the Congress for the New Urbanism. His book Visions for a New American Dream was published by the American Planning Association. His current book What People Want is in first draft.

John Peponis is an architect and a professor of architecture at the Georgia Institute of Technology. He received his Ph.D. in architecture at University College London in 1983. He teaches regularly at the National Technical University of Athens, The University of London and the Chalmers University of Technology. $\mathrm{He}$ is a member of the editorial boards of Environment and Planning B: Planning and Design and The J ournal of Architecture as well as a member of the steering and refereeing committees for the biannual International Symposia on Space Syntax. Most recently he has co-authored an overview of "space syntax" for the Handbook of Environmental Psychology (Bechtel and Churchman eds).

Michael Southworth is Professor in both the Department of City and Regional Planning and the
Department of Landscape Architecture and Environmental Planning at the University of California at Berkeley. Trained and professionally registered in both city planning and architecture, he received the Ph.D. and M.C.P. degrees from the Massachusetts Institute of Technology, and the Bachelor of Architecture and Bachelor of Arts from the University of Minnesota. He is a Fellow of the American Institute of Architects and a member of the American Institute of Certified Planners. His recent books include: Streets and the Shaping of Towns and Cities (with Eran BenJoseph, 2003), City Sense and City Design (as editor and contributor with Tridib Banerjee) and Wasting Away (by Kevin Lynch).

Daniel Stokols is Professor of Planning, Policy, and Design and Dean Emeritus of the School of Social Ecology at the University of California, Irvine. Dr. Stokols received his $B$.A. degree at the University of Chicago and his M.A. and Ph.D. degrees at the University of North Carolina, Chapel Hill. He is past President of the Division of Population and Environmental Psychology of the American Psychological Association (APA). 
Dr. Stokols was a recipient of the Annual Educator Award from the

International Facility Management Association in 1988, the Annual

Career Award of the Environmental

Design Research Association in 1991,

and the $\mathrm{UCl}$ Lauds and Laurels

Faculty Achievement Award in 2003. 


\section{Appendix 2: Qualitative Definitions of Urban Design Qualities}

\section{I mageability}

Imageability is the quality of a place that makes it distinct, recognizable, and memorable. A place has high imageability when specific physical elements and their arrangement capture attention, evoke feelings, and create a lasting impression.

\section{Discussion}

Kevin Lynch (1960) defines

imageability as a quality in a physical object that gives it a high probability of evoking a strong image in any given observer: "It is that shape, color, or arrangement which facilitates the making of vividly identified, powerfully structured, highly useful mental images of the environment." A highly imageable city is well formed, contains distinct parts, and is instantly recognizable to anyone who has visited or lived there. It plays to the innate human ability to see and remember patterns. It is one whose elements are easily identifiable and grouped into an overall pattern.

Landmarks are a key component of imageability. The term "landmark" does not necessarily denote a grandiose civic structure or even a large object. In the words of Lynch, it can be "a doorknob or a dome." What is essential is its singularity and location, in relationship to its context, background, and the city at large. Landmarks are a principle of urban design because they act as visual termination points, orientation points, and points of contrast in the urban setting. Tunnard and Pushkarev

(1963, p. 140) attribute even greater importance to landmarks, saying "A landmark lifts a considerable area around itself out of anonymity, giving it identity and visual structure." I mageability is related to "sense of place." Gorden Cullen (1961, p. 152) elaborates on the concept of a "sense of place," asserting that a characteristic visual theme will contribute to a cohesive sense of place, and will inspire people to enter and rest in the space. Jan Gehl (1987, p. 183) explains this phenomena using the example of famous Italian city squares, where "life in the space, the climate, and the architectural quality support and complement each other to create an unforgettable total impression."

When all factors manage to work together to such pleasing ends, a feeling of physical and psychological well-being results: the feeling that a space is a thoroughly pleasant place in which to be.

Imageability is influenced by many other urban design qualities legibility, enclosure, human scale, transparency, linkage, complexity, and coherence - and is in some way the net effect of these qualities. Places that rate high on these qualities are likely to rate high on imageability as well - the neighborhoods of Paris or San Francisco, for example. However, places that rate low on these qualities may also evoke strong images, though ones that people may prefer to forget. Although the strength of the image a place evokes, whether positive or negative, is itself of interest, urban designers focus on the strength of positive images in discussing imageability and sense of place.

\section{Legibility}

Legibility refers to the ease with which the spatial structure of a place can be understood and navigated as a whole. The legibility of a place is improved by a street or pedestrian network that provides travelers with a sense of orientation and relative location and by physical elements that serve as reference points. 


\section{Discussion}

The dictionary defines legibility as "possible to read or decipher, plainly discernible, or apparent." As described by Kevin Lynch in his classic, The Image of the City, legibility is the apparent clarity of the cityscape, the "ease by which its parts can be recognized and can be organized into a coherent pattern." Lynch suggests that when faced with a new place, people automatically create a mental map that divides the city into paths, edges, districts, nodes, and landmarks. Places with strong edges, distinct landmarks, and busy nodes allow people to form detailed and relatively accurate mental maps. Conversely, a city that has no definite edges, nodes, or visually interesting features, will be difficult to make sense of and to remember. Legibility facilitates wayfinding, the process by which people move successfully through the physical environment to reach a desired destination, determining a route between two points, choosing an alternate route when the primary route is impassable, navigating along a route, and learning a new spatial environment.

The layout of the street network has an important influence on legibility, although the influence is sometimes ambiguous. A regular grid of streets makes it easy for people to navigate even when they are unfamiliar with a place, although it does not provide a way of distinguishing one block from another. An irregular pattern of streets, in which blocks are of irregular length and compass orientation changes from block to block, may increase the difficulty of navigating and learning the network, although it distinguishes each block with different lengths and orientations. The street network thus works together with other elements of the physical environment to determine the legibility of a place. Signage, in particular, helps to distinguish one point from another and to orient and direct a traveler through the network. Landmarks, which have an important influence on imageability, also play an important role in mental maps and thus help to increase the legibility of a place. Visual termination and deflection points also contribute to legibility. Visual termination creates a "focal point, the vertical symbol of congregation" (Cullen 1961, p. 26). "...in the fertile streets.. it is the focal point which crystallizes the situation, which confirms 'this is the spot', 'Stop looking, it is here.'" Recently, the New Urbanism movement has embraced the concept of visual termination. Andres Duany and Elizabeth Plater-Zyberk (1992), pioneers of this movement, say that visual terminations focus the community, as well as put a definite end point to streets to keep them from going on forever. On a large scale, visual termination points can include large civic buildings,

prominent landmarks, or elements of nature. On a smaller, neighborhood scale, visual termination can be created by the use of gazebos, bends in the roads, or other small-scale elements. Allan Jacobs (1993, p. 297) says of streets, "Since they have to start and stop somewhere, these points should be well marked." He argues that clearly marked end points both serve as reference points and give a sense of definition to an area.

To our knowledge, only visual assessment study has attempted to measure legibility, this in connection with natural rather than urban landscapes (Herzog and Leverich 2003). Legibility was highly correlated with another perceptual quality, coherence. The hypothesized relationship to landmarks proved to be weak. 


\section{Enclosure}

Enclosure refers to the degree to which streets and other public spaces are visually defined by buildings, walls, trees, and other vertical elements. Spaces where the height of vertical elements is proportionally related to the width of the space between them have a room-like quality.

\section{Discussion}

Outdoor spaces are defined and shaped by vertical elements, which interrupt viewers' lines of sight. A sense of enclosure results when lines of sight are so decisively blocked as to make outdoor spaces seem roomlike. Gordon Cullen (1961) states that "Enclosure, or the outdoor room, is, perhaps, the most powerful, the most obvious, of all the devices to instill a sense of position, of identity with the surroundings.... it embodies the idea of hereness..." Christopher Alexander et al. (1977, p. 106) say that "An outdoor space is positive when it has a distinct and definite shape, as definite as the shape of a room, and when its shape is as important as the shapes of the buildings which surround it. Likewise, Allan Jacobs (1993) says that people react favorably to fixed boundaries as something safe, defined, and even memorable-an invitation to enter a place special enough to warrant boundaries. Jacobs and Appleyard (1987) speak of the need for buildings to "define or even enclose space-rather than sit in space." Richard Hedman (1984) refers to certain arrangements of buildings creating intensely three dimensional spaces.

In an urban setting, enclosure is formed by lining the street or plaza with unbroken building fronts of roughly equal height. The buildings become the "walls" of the outdoor room, the street and sidewalks become the "floor," and if the buildings are roughly equal height, the sky projects as an invisible ceiling. Buildings lined up that way are often referred to as "street walls." Alexander et al. (1977, pp. 489-491) state that the total width of the street, building-to-building, should not exceed the building heights in order to maintain a comfortable feeling of enclosure. Allan Jacobs (1993) is more lenient in this regard, suggesting that the proportion of building heights to street width should be at least 1:2. Other designers have recommended proportions as high as 3:2 and as low as $1: 6$ for a sense of enclosure.
At low suburban densities, building masses become less important in defining space, and street trees assume the dominant role. Rows of trees on both sides of a street can humanize the height-to-width ratio. Henry Arnold (1993) explains that trees define space both horizontally and vertically. Horizontally they do so by visually enclosing or completing an area of open space. Vertically they define space by creating an airy ceiling of branches and leaves.

Unlike the solid enclosure of buildings, tree lines depend on visual suggestion and illusion. Street space will seem enclosed only if trees are closely spaced. Properly scaled, walls and fences can also provide spatial definition in urban and suburban settings. Kevin Lynch recommended walls and fences that are either low or over six feet tall.

Visual termination points may also contribute to a sense of enclosure. Andres Duany and other New Urbanists advocate closing vistas at street ends with prominent buildings, monuments, fountains, or other architectural elements as a way of achieving enclosure in all directions (Duany and Plater-Zyberk 1992). When a street is not strongly defined by buildings, focal points at its ends can maintain the visual linearity of 
the arrangement. Similarly, the layout of the street network can influence the sense of enclosure. A rectilinear grid with continuous streets creates long sight lines that may offset the sense of enclosure created by the buildings and trees that line the street. I rregular grids may create visual termination points that help to enclose a space; cul-desacs, for example, tend to create more sense of enclosure than through streets.

Enclosure is eroded by breaks in the continuity of the street wall, that is, breaks in the vertical elements such as buildings or tree rows that line the street. Breaks in continuity that are occupied by non-active uses create dead spaces that further erode enclosure; vacant lots, parking lots, driveways, and other uses that do not generate human activity and presence are all considered dead spaces. Large building setbacks are another source of dead space.

Alexander et al. (1997) say "building setbacks from the street, originally invented to protect the public welfare by giving every building light and air, have actually helped greatly to destroy the street as social space."

\section{Human Scale}

Human scale refers to a size, texture, and articulation of physical elements that match the size and proportions of humans and, equally important, correspond to the speed at which humans walk. Building details, pavement texture, street trees, and street furniture are all physical elements contributing to human scale.

\section{Discussion}

The urban design glossary for the City of Seattle defines human scale as "the quality of a building that includes structural or architectural components of size and proportions that relate to the human form and/or that exhibits through its structural or architectural components the human functions contained within." Modest sized buildings, narrow streets and small spaces create an intimate environment, and the opposite for large buildings, streets and spaces. Urban designers offer differing definitions of human scale. Alexander et al. (1977) state that any buildings over four stories tall are out of human scale. Lennard and Lennard (1987) set the limit at six stories. Hans Blumenfeld (1953) sets it at three stories. In taller buildings, Roger Trancik (1986) says that lower floors should spread out and upper floors step back before they ascend, giving human-scale definition to streets and plazas. Richard Hedman (1984) emphasizes the importance of articulated architecture and belt courses and cornices on large buildings to help define street space and scale. Several authors suggest that the width of buildings, not just the height, defines human scale. For human scale, building widths should not be out of proportion with building heights, as are so many buildings in the suburbs. In what was billed as the first of its kind, Stamps (1998) used a visual assessment survey to explore perceptions of architectural mass. The most important determinant was the cross sectional area of buildings, second was the amount of fenestration, and third was the amount of façade articulation and partitioning.

Human scale can also be defined by human speed. Jane Holtz Kay (1997) argues that today, far too many things are built to accommodate the bulk and rapid speed of the automobile; we are "designing for 60 mph." When approached by foot, these things overwhelm the senses, creating disorientation. For example, large signs with large lettering are designed to be read by high-speed 
motorists. For pedestrians, small signs with small lettering are much more comfortable.

Personal interaction distances play a role in designing for the human scale. Jan Gehl (1987) designates these distances as:

Intimate distance Personal distance Social distance

$$
0-1.5 \mathrm{ft}
$$$$
1.5-4.5 \mathrm{ft}
$$
$4.5-12 \mathrm{ft}$

Public distance

According to Alexander et al. (1977), a person's face is just recognizable at 70 feet, a loud voice can just be heard at 70 feet, and a person's face is recognizable in portrait-like detail up to about 48 feet. These set the limits of human scale for social interaction.

Street trees can moderate the scale of tall buildings and wide streets. According to Henry Arnold (1993), where tall buildings or wide streets would intimidate pedestrians, a canopy of leaves and branches allows for a simultaneous experience of the smaller space within the larger volume. He posits that where streets are over 40 feet wide, additional rows of trees are needed to achieve human scale. Hedman (1984) recommends the use of other small-scale elements such as clock towers to moderate the scale of buildings and streets.

\section{Transparency}

Transparency refers to the degree to which people can see or perceive what lies beyond the edge of a street or other public space and, more specifically, the degree to which people can see or perceive human activity beyond the edge of a street or other public space. Physical elements that influence transparency include walls, windows, doors, fences, landscaping, and openings into midblock spaces.

\section{Discussion}

Taken literally, transparency is a material condition that is pervious to light and/or air, an inherent quality of substance as in a glass wall. As an element of design, transparency has two meanings: an ability to see beyond the street edge and signs of habitation beyond the street edge. A classic example of transparency is a shopping street with display windows that invite passersby to look in and then come in to shop. Blank walls and reflective glass buildings are classic examples of the elements that reduce transparency.

But transparency can be subtler than this. What lies behind the street edge need only be imagined, not actually seen. Allan Jacobs (1993) says that streets with many entryways contribute to the perception of human activity beyond the street, while those with blank walls and garages suggest that people are far away. Even blank walls may exhibit some transparency if overhung by trees or bushes, providing signs of habitation. Henry Arnold (1993) tells us that trees with high canopies create "partially transparent tents, " affording awareness of the space beyond while still conferring a sense of enclosure. By contrast, small trees in most urban settings work against transparency (Arnold 1993). Transparency is most critical at the street level, because this is where the greatest interaction occurs between indoors and outdoors. William $\mathrm{H}$. Whyte (1988) opined that if a blank wall index were ever computed, as the percentage of blockfront up to 35-foot height that is blank, it would show that blank walls have become the dominant feature of cityscapes.

\section{Linkage}

Linkage refers to physical and visual connections from building to street, building to building, space to space, or one side of the street to the other 
which tend to unify disparate elements. Tree lines, building projections, marked crossings all create linkage. Linkage can occur longitudinally along a street or laterally across a street.

\section{Discussion}

Linkages can be defined as features that promote the interconnectedness of different places and that provide convenient access between them. Linkage is closely associated with the concept of connectivity, as both are concerned with the ease of movement in an area and depend on the relationships between paths and nodes. Jacobs (1993) recommends urban street connections at most every 300 feet. Alexander et al. (1977) give similar advice, suggesting pedestrian road crossings every 200 or 300 feet. They advocate the use of a separate pedestrian-only network running orthogonal to the street grid to maximize pedestrian accessibility. Duany and Plater-Zyberk (1992) generally limit the size of blocks to 230 by 600 feet to ensure reasonable travel distances. On the other hand, Appleyard (1981) argues against too much connectivity in residential areas since through traffic can erode a sense of community, and suggests breaking up the gridiron with barriers and diverters.

Linkages between the street and surrounding buildings are also important and may be psychological as well as physical. Maintenance of sight lines and sidewalk connections are obvious ways to provide this kind of linkage, but it can also be provided in more subtle ways. For example, Henry Arnold (1993) advocates the use of trees for linkage: continuous tree rows can psychologically connect places at either end, and tree patterns that reflect or amplify building geometry can psychologically link buildings to the street. As Roger Trancik (1986) puts it: "Urban design is concerned with the question of making comprehensible links between discrete things." In this way, the concept of linkage is closely related to the concept of legibility.

\section{Complexity}

Complexity refers to the visual richness of a place. The complexity of a place depends on the variety of the physical environment, specifically the numbers and kinds of buildings, architectural diversity and ornamentation, landscape elements, street furniture, signage, and human activity.

\section{Discussion}

Amos Rapoport (1990) explains the fundamental properties of complexity. Complexity is related to the number noticeable differences to which a viewer is exposed per unit time. Human beings are most comfortable receiving information at perceivable rates. Too little information produces sensory deprivation, too much creates sensory overload. Rapoport contrasts the complexity requirements of pedestrians and motorists. Slow moving pedestrians require a high level of complexity to hold their interest. Fast moving motorists will find the same environment chaotic. The commercial strip is too complex and chaotic at driving speeds, yet due to scale, yields few noticeable differences at pedestrian speeds. The environment can provide low levels of usable information in three ways: elements may be too few or too similar; elements, though numerous and varied, may be too predictable for surprise or novelty; or elements, though numerous and varied, may be too unordered for comprehension. Pedestrians are apt to prefer streets high in complexity, since they provide interesting things to look at: building details, signs, people, surfaces, changing light 
patterns and movement, signs of habitation. As Jan Gehl notes in his book Life Between Buildings, an interesting walking network will have the "psychological effect of making the walking distance seem shorter," by virtue that the trip is "divided naturally, into manageable stages." Complexity results from varying building shapes, sizes, materials, colors, architecture, and ornamentation. According to Jacobs and Appleyard (1987), narrow buildings in varying arrangements add to complexity, while wide buildings subtract. Allan Jacobs (1993) refers to the need for many different surfaces over which light is constantly moving in order to keep eyes engaged. Tony Nelessen (1994) asserts that "Variations on basic patterns must be encouraged in order to prevent a dull sameness. If a particular building or up to three buildings are merely repeated, the result will be boring and mass produced." Variation can be incorporated into the building orientation plan or building set-back line, allowing for varied building frontage instead of monotonous, straight building frontage. Numerous doors and windows produce complexity as well as transparency.
Complexity is one perceptual quality that has been measured extensively in visual assessment studies. It has been related to changes in texture, width, height, and setback of buildings (Elshestaway 1997). It has been related to building shapes, articulation, and ornamentation (Stamps 1999; Heath et al. 2000). Other elements of the built environment also contribute to complexity. According to Henry Arnold (1993), one function of trees is to restore the rich textural detail missing from modern architecture. Light filtered through trees gives life to space. Manipulation of light and shade transforms stone, asphalt, and concrete into tapestries of sunlight and shadow. Allan Jacobs (1993) similarly values to the constant movement of branches and leaves, and ever-changing light that play on, through, and around them. Street furniture also contributes to the complexity of street scenes. Jacobs (1993) states that pedestrian-scaled streetlights, fountains, carefully thought out benches, special paving, even public art, combine to make regal, special places.

Signage is a major source of complexity in urban and suburban areas. If well done, signs can add visual interest, make public spaces more inviting, and help create a sense of place. Gordon Cullen (1961, p. 151) calls advertisement signs "the most characteristic, and, potentially, the most valuable, contribution of the twentieth century to urban scenery." When these signs are lit up at night, the result can be spectacular. However, signage must not be allowed to become chaotic and unfriendly to pedestrian traffic. Nasar (1987) reports that people prefer signage with moderate rather than high complexity-measured by the amount of variation among signs in location, shape, color, direction, and lettering style. Allan Jacobs (1993) uses Hong Kong signage as an example of complexity to the point of chaos.

The presence and activity of people add greatly to the complexity of a scene. This is true not only because people appear as discrete "objects," but because they are in constant motion. Jan Gehl (1987, p. 25) explains that "people are attracted to other people. They gather with and move about with others and seek to place themselves near others. New activities begin in the vicinity of events that are already in progress." Allan Jacobs, in the course of his world wide travels, found that the most popular streets were ones that 
contained "sidewalks fairly cluttered with humans and life," calling them an "attractive obstacle courses" that never failed to entertain.

Complexity can also arise at a larger scale from the pattern of

development. According to

Christopher Alexander (1965),

organically developed older cities have complex "semi-lattice"

structures, while new planned developments have simple "tree-like structures." Integration of land uses, housing types, activities,

transportation modes, and people creates diversity, and that in turn adds to complexity (Gehl 1987). Jane Jacobs (1961, p. 161) describes diversity as a mixture of commercial, residential, and civic uses in close proximity to each other, creating human traffic throughout day and night, and subsequently benefiting the safety, economic functioning, and appeal of a place.

\section{Coherence}

Coherence refers to a sense of visual order. The degree of coherence is influenced by consistency and complementarity in the scale, character, and arrangement of buildings, landscaping, street furniture, paving materials, and other physical elements.

\section{Discussion}

Coherence refers to the orderly arrangement of physical elements in the environment (Kaplan and Kaplan 1989 , p. 54). Allan Jacobs (1993, p. 287) describes coherence in architecture as follows: “...buildings on the best streets will get along with each other. They are not the same, but they express respect for one another, most particularly in respect to height and the way they look." According to Henry Arnold (1993), complexity of architecture of earlier eras was given coherence by common materials, handcrafted details, and reflections of human use. Because these are absent from today's architecture, landscaping becomes critical for creating a sense of visual unity; shade trees planted close together result in an uninterrupted pattern of light and shade, unifying a scene. At the city level, coherence takes the form of orderly density patterns and hierarchies of communal spaces (Alexander et al 1977). Nikos Salingaros, applying mathematical principles to the urban setting, concludes, "Geometrical coherence is an identifiable quality that ties the city together through form, and is an essential prerequisite for the vitality of the urban fabric."
Richard Hedman (1984, p. 29) warns that when every building seeks to be a unique statement and the center of attention, there is an unexpected effect-“instead of providing an exciting counterpoint, the addition of each new and different building intensifies the impression of a nervous, irritating confusion." $\mathrm{He}$ goes on to list multiple features of buildings that, when repeated, can create visual unity: building silhouettes, spacing between buildings, setbacks from street, proportions of windows/bays/doorways, massing of building form, location of entryways, surface material and finish, shadow patterns, building scale, style of architecture, and landscaping. While often presented as opposites, coherence and complexity represent distinct perceptual dimensions.

Visual preference surveys show that viewers do not appreciate massive doses to unstructured information. People like complexity, but not the unstructured complexity of the commercial strip. Scenes with high complexity and low coherence tend to be least liked, causing Herzog et al. (1982) to conclude that, "High complexity urban areas must also be highly coherent." In one such survey, Nasar (1987) found that people 
preferred signage that is moderate complex and highly coherent.

Generalizing across many surveys, Kaplan and Kaplan (1989, p. 54)

deem scenes of low complexity and

high coherence as "boring," scenes of

high complexity and low coherence as "messy," but scenes of high

complexity and high coherence as

"rich and organized." It is important

to note that coherence does not

imply mindless repetition or

blandness, rather continuity of design and thematic ordering. 


\section{Appendix 3: Operational Definitions of Physical Features}

Variable Long Name $\quad$ Variable Type Counting Criteria Measurement Protocol

\begin{tabular}{lll} 
courtyards/plazas/parks - both sides & $\begin{array}{l}\text { pass camera or } \\
\text { within } 50 \text { feet, } \\
\text { both sides }\end{array}$ & $\begin{array}{l}\text { Count individual courtyards, plazas, parks that the camera passes on either side of the street } \\
\text { or that are within } 50 \text { feet from the camera. Large parks that occupy a whole block will still } \\
\text { count as one park. }\end{array}$ \\
\hline arcade - same side & $\begin{array}{l}\text { count } \\
\text { dummy }\end{array}$ & $\begin{array}{l}\text { Indicate the presence of an arcade. An arcade will be defined as a covered passageway } \\
\text { which allows the passageway to be protected from rain and direct sun, while retaining the } \\
\text { advantages of an outdoor space. Count arcades regardless if the camera is inside or outside } \\
\text { the arcade. }\end{array}$ \\
\hline
\end{tabular}

Count number of landmarks. Landmark must be at least $20 \%$ of the screen height. Landmarks are defined as a building or structure that stands out from the background buildings. The

reference point for orientation and for providing directions to visitors.

types of landmarks text

count
List landmarks counted.

Count views of mountain ranges, bodies of water, and other man made features that incorporate the surrounding environment (a marina) that would serve as natural landmarks. The major landscape feature should be prominent and/or well known that it could be plausibly used as a reference point for orientation and for providing directions to visitors. The feature should occupy at least $20 \%$ of the screen height. 

memorable architecture

dummy

$1=$ yes $0=n$

Indicate the presence of memorable architecture. This is defined as more than just well designed buildings. Memorable architecture implies that the scene as a whole contains architecture that makes the scene prominent and/or well known. The scene as a whole could be plausibly used as a reference point for orientation and for providing directions to visitors. A counted buildings well known landmark can serve as memorable architecture

distinctive signage

or passed, or

$20 \%$ screen

height, both sides; Indicate the presence of distinctive signage. A sign is distinctive if it is prominent and/or well known that it could be plausibly used as a reference point for orientation and for providing

$\quad 1=$ yes $0=$ no same side
directions to visitors. The occurrences of distinctive signage should occupy at least $20 \%$ of same side the screen height or be within 50 feet of the camera.

\begin{abstract}
tons
\end{abstract}
terminated vista

dummy

$1=$ yes $0=$ no

1000 feet ahead

feet into the distance.

Estimate how far the camera has traveled in relation to the end of the block. Instances where a street that intersects with the opposite side of the street but not with the side where the camera is traveling (a t-intersection) will not be considered as the end of the block if the intersecting street appears to be minor (less than 2 marked lanes, no signalization, no marked 
proportion of distance walked versus distance \begin{tabular}{l} 
proportion \\
visible \\
\hline
\end{tabular} $\min .05$
Estimate how far the camera has traveled in relation to the most distant feature seen. Enter 0.05 if distance beyond seems infinite. Use 0.10 intervals. Use the same value as progress toward next intersection if farthest distance visible is the end of the block.

Count buildings along street and in the distance that occupy at least $20 \%$ of screen height.

Count different land uses observed on both sides of street. Land use distinctions are civic/community, residential, lodgings, office, medical, retail (includes restaraunts and shops), entertainment, transit station, and park. Parking, even in a structure, will not be considered a

proportion of historic building frontage - both sides counted buildings,

and fronting along Estimate the proportion of the street fronted by buildings that is fronted by buildings that are street and passed historic. Architecture that can be determined to have originated from the World War II era or or 500 feet ahead, before will be considered as historic. Relevant frontage is defined as the total distance the both sides camera travels plus an additional 500 feet ahead from the end of the video clip. 


\begin{tabular}{|c|c|c|c|}
\hline Variable Long Name & Variable Type & Counting Criteria & Measurement Protocol \\
\hline $\begin{array}{l}\text { number of buildings with identifiers - both } \\
\text { sides }\end{array}$ & count & $\begin{array}{l}\text { counted buildings, } \\
\text { and fronting along } \\
\text { street and passed } \\
\text { or } 500 \text { feet ahead, } \\
\text { both sides }\end{array}$ & $\begin{array}{l}\text { Count buildings whose use can be determined by building features. For example, a church } \\
\text { can be identified by a steeple. Stores can be identified by signs that can be easily read in the } \\
\text { video clip. If a building has been subdivided by several occupants, only count the building as } \\
\text { indentifiable if a majority of the occupants' uses can be determined by building features. }\end{array}$ \\
\hline proportion of building frontage with identifiers & proportion & $\begin{array}{l}\text { counted buildings, } \\
\text { and fronting along } \\
\text { street and passed } \\
\text { or } 500 \text { feet ahead, } \\
\text { both sides }\end{array}$ & $\begin{array}{l}\text { Determine the building frontage whose uses can be determined by building features. Relevant } \\
\text { frontage is defined as the total distance the camera travels plus an additional } 500 \text { feet ahead } \\
\text { from the end of the video clip. }\end{array}$ \\
\hline various building ages & $\begin{array}{l}\text { dummy } \\
1=\text { yes } 0=\text { no }\end{array}$ & $\begin{array}{l}\text { at least } 1 \text { counted } \\
\text { building from } \\
\text { different period }\end{array}$ & $\begin{array}{l}\text { Indicate whether buildings appear to have been built at different time periods. At least one } \\
\text { counted building must appear to be built in a different time period. }\end{array}$ \\
\hline
\end{tabular}

Count different primary building materials for buildings that have been counted. Glass counts number of primary building materials count counted buildings as a building material only if it makes up the entire building.

counted buildings

of a building is different than the building, the roof color will count as an accent color. 


\begin{tabular}{|c|c|c|c|}
\hline Variable Long Name & Variable Type & Counting Criteria & Measurement Protocol \\
\hline number of accent colors - both sides & count & $\begin{array}{l}\text { counted buildings, } \\
\text { objects that } \\
\text { occupy } 20 \% \text { of } \\
\text { screen height or } \\
\text { within } 50 \text { feet, } \\
\text { both sides }\end{array}$ & $\begin{array}{l}\text { Count number of accent colors. Accent colors contrast the dominant building colors and can } \\
\text { come from street furniture, awnings, business signs, and building trim. Accent colors will be } \\
\text { counted only from objects that meet one of the counting conventions. The object must at least } \\
\text { occupy } 20 \% \text { of the screen height or be within } 50 \text { feet from the camera. }\end{array}$ \\
\hline
\end{tabular}

accent colors

text

List counted accent colors.

at least 5 feet,

passed or 50 feet

ahead, same side
Count building projections (such as porches, stoops,marquees, decks, balconies, window bays, etc...) that project at least 5 feet from the building and are from buildings that have been counted that front the street, and that are passed or within 50 from the camera at the end of the clip. $\underline{\text { building projections - same side }}$ count count passed or 50 feet ahead, same side
Count sets of doors that the camera passes or that are within 50 feet from the camera on the same side of the street. Do not assume the location of doors or count doors seen in window reflections. proportion of counted sets of door that are recessed proportion

fronting along

street, and passed

or 50 feet ahead,

and set back no

more than 50 feet

proportion of first floor façade that has windows - same side proportion
Divide visible recessed doors by visible sets of doors.

Estimate the proportion of the first floor of buildings that front the street on the same side that are passed or within 50 feet from the camera at the end of the clip that is window. Use 0.10 intervals. 


\begin{tabular}{|c|c|c|c|}
\hline Variable Long Name & Variable Type & Counting Criteria & Measurement Protocol \\
\hline $\begin{array}{l}\text { proportion of entire façade that has windows - } \\
\text { same side }\end{array}$ & proportion & $\begin{array}{l}\text { fronting along } \\
\text { street, and passed } \\
\text { or } 50 \text { feet ahead, } \\
\text { and set back no } \\
\text { more than } 50 \text { feet } \\
\text { same side }\end{array}$ & $\begin{array}{l}\text { Estimate the proportion of the entire surface of buildings that front the street on the same side } \\
\text { that are passed or within } 50 \text { feet from the camera at the end of the clip that is window. Use } \\
0.10 \text { intervals. }\end{array}$ \\
\hline common window proportions - both sides & $\begin{array}{l}\text { dummy } \\
1=\text { yes } 0=\text { no }\end{array}$ & $\begin{array}{l}\text { at least } 80 \% \text { of } \\
\text { counted buildings } \\
\text { fronting along } \\
\text { street and passed } \\
\text { or } 500 \text { feet ahead, } \\
\text { both sides }\end{array}$ & $\begin{array}{l}\text { Indicate whether windows have common proportions. Common window proportions occur } \\
\text { when at least } 80 \% \text { of windows on all buildings are predominantly vertical or horizontal and } \\
\text { have similar architectural trim. If a building on one of the sides has no window than there is no } \\
\text { common window proportions. }\end{array}$ \\
\hline awnings or overhangs - both sides & count & $\begin{array}{l}\text { counted buildings } \\
\text { fronting along } \\
\text { street and passed } \\
\text { or } 50 \text { feet ahead, } \\
\text { both sides }\end{array}$ & $\begin{array}{l}\text { Count number of awnings or overhangs on buildings that have been counted on both sides of } \\
\text { street and that are passed or are within } 50 \text { feet from the camera at the end of the clip. }\end{array}$ \\
\hline height interruptions - same side & proportion & $\begin{array}{l}\text { counted buildings } \\
\text { fronting along } \\
\text { street and passed } \\
\text { or } 50 \text { feet ahead, } \\
\text { same side }\end{array}$ & $\begin{array}{l}\text { Estimate proportion of building frontage that have been counted on the same side that front } \\
\text { the street and are within } 50 \text { feet from the camera at the end of the video clip with belt courses } \\
\text { or other visual interruptions to building height. One storey buildings should be considered as } \\
\text { height interrupted. Use } 0.10 \text { intervals. }\end{array}$ \\
\hline $\begin{array}{l}\text { number of buildings with non-rectangular } \\
\text { silhouettes }\end{array}$ & count & counted buildings & $\begin{array}{l}\text { Count buildings that have been counted whose shape is not a simple rectangular box. Pitched } \\
\text { roofs on buildings that are viewed at an angle and make the building look non-rectangluar do } \\
\text { count as non-rectangular. Building roof trim that makes variations in an otherwise simple } \\
\text { rectangular shape do also count as non-rectangular. }\end{array}$ \\
\hline $\begin{array}{l}\text { proportion of buildings with non-rectangular } \\
\text { silhouettes }\end{array}$ & proportion & & Divide number of buildings with non-rectangular silhouettes by number of counted buildings. \\
\hline common architectural style - both sides & $\begin{array}{l}\text { dummy } \\
1=\text { yes } 0=\text { no }\end{array}$ & $\begin{array}{l}\text { at least } 80 \% \text { of } \\
\text { counted buildings } \\
\text { fronting along } \\
\text { street and passed } \\
\text { or } 500 \text { feet ahead, } \\
\text { both sides }\end{array}$ & $\begin{array}{l}\text { Indicate the presence of common architectural styles. Common architectural styles occurs } \\
\text { when at least } 80 \% \text { of the counted buildings that front the street and that have been passed or } \\
\text { are within } 500 \text { feet from the camera at the end of the video clip use similar architectural styles } \\
\text { and/or have consistent building trim and roof pitch. }\end{array}$ \\
\hline
\end{tabular}




\begin{tabular}{|c|c|c|c|}
\hline Variable Long Name & Variable Type & Counting Criteria & Measurement Protocol \\
\hline common materials - both sides & $\begin{array}{l}\text { dummy } \\
1=\text { yes } 0=\text { no }\end{array}$ & $\begin{array}{l}\text { at least } 80 \% \text { of } \\
\text { counted buildings } \\
\text { fronting along } \\
\text { street and passed } \\
\text { or } 500 \text { feet ahead, } \\
\text { both sides }\end{array}$ & $\begin{array}{l}\text { Indicate the presence of common building materials. Common building materials occurs when } \\
\text { at least } 80 \% \text { of the counted buildings that front the street and that have been passed or are } \\
\text { within } 500 \text { feet from the camera at the end of the video clip use the same primary building } \\
\text { material. }\end{array}$ \\
\hline proportion active uses - same side & proportion & $\begin{array}{l}\text { counted buildings } \\
\text { fronting along } \\
\text { street and passed } \\
\text { or } 50 \text { feet ahead, } \\
\text { same side }\end{array}$ & $\begin{array}{l}\text { Determine proportion of street frontage that has active uses. Active uses are defined as } \\
\text { shops, restaraunts, public park, and other uses that generate significant pedestrian traffic. } \\
\text { Inactive uses include blank walls, parking lots, vacant lots, abandoned buildings, and office } \\
\text { with no apparent activity. In Regards to residential uses, when the density appears to be more } \\
\text { than } 10 \text { units per acre, assume the land use to be active. The street frontage will be defined } \\
\text { as the total distance traveled by the camera plus an additional } 50 \text { feet ahead from the end of } \\
\text { the video clip. }\end{array}$ \\
\hline proportion street wall - same side & proportion & $\begin{array}{l}\text { counted buildings } \\
\text { fronting along } \\
\text { street and passed } \\
\text { or } 500 \text { feet ahead, } \\
\text { same side }\end{array}$ & $\begin{array}{l}\text { Determine proportion of street that is occupied by a continuous wall or facade adjacent to the } \\
\text { sidewalk. Facades set back by parking or lawn and driveways do not count as street wall. } \\
\text { Intersecting streets and ends of blocks however should not count against street wall. The } \\
\text { street will be defined as the total distance the camera travels plus an additional } 500 \text { feet } \\
\text { ahead from the end of the video clip. }\end{array}$ \\
\hline proportion street wall - opposite side & proportion & $\begin{array}{l}\text { counted buildings } \\
\text { fronting along } \\
\text { street and passed } \\
\text { or } 500 \text { feet ahead, } \\
\text { opposite side }\end{array}$ & $\begin{array}{l}\text { Determine proportion of street that is occupied by a continuous wall or facade adjacent to the } \\
\text { sidewalk. Facades set back by parking or lawn do not count as street wall. Driveways also do } \\
\text { not count as street wall. Intersecting streets and ends of blocks however should not count } \\
\text { against street wall. The street will be defined as the total distance the camera travels plus an } \\
\text { additional } 500 \text { feet ahead from the end of the video clip. }\end{array}$ \\
\hline enclosed sides & count & $\begin{array}{l}\text { at least } 80 \% \text { of } \\
\text { frontage passed } \\
\text { or } 500 \text { feet ahead } \\
\text { that is blocked, } \\
\text { both sides }\end{array}$ & $\begin{array}{l}\text { Indicate the number of sides of the street that are enclosed. Maximum number is } 3 \text { (front, } \\
\text { same side, opposite side). A side is considered enclosed if } 80 \% \text { of the frontage on that side is } \\
\text { blocked by buildings or other featrues that are opaque at street level whether or not they front } \\
\text { along the sidewalk. If the street has a terminated by a vista then the front is enclosed. } \\
\text { Relevant frontage is defined as the total distance the camera travels plus an additional } 500 \\
\text { feet ahead from the end of the video clip. }\end{array}$ \\
\hline $\begin{array}{l}\text { average building setback from sidewalk or } \\
\text { travel path - same side }\end{array}$ & dimension & $\begin{array}{l}\text { passed on the } \\
\text { same side or } 50 \mathrm{ft} \\
\text { ahead }\end{array}$ & $\begin{array}{l}\text { Estimate the average setback of buildings from the sidewalk or travel path on the same side. } \\
\text { Buildings that front directly on the sidewalk have a setback of } 0 \text {. }\end{array}$ \\
\hline common setbacks - both sides & $\begin{array}{l}\text { dummy } \\
1=\text { yes } 0=\text { no }\end{array}$ & $\begin{array}{l}\text { no more than } 30 \% \\
\text { variance for } \\
\text { buildings fronting } \\
\text { along street and } \\
\text { passed or } 500 \text { feet } \\
\text { ahead, both sides }\end{array}$ & $\begin{array}{l}\text { Indicate whether buildings that have been counted, that front along the street, and are within } \\
500 \text { feet from the camera at the end of the video clip have a common setback. Common } \\
\text { setbacks occure when all building setbacks vary no more than } 30 \% \text {. Recessed courtyards and } \\
\text { other small breaks in street wall that can be determined as part of a building do not negate the } \\
\text { presense of common setbacks. }\end{array}$ \\
\hline
\end{tabular}




\begin{tabular}{|c|c|c|c|}
\hline Variable Long Name & Variable Type & Counting Criteria & Measurement Protocol \\
\hline building height - same side & dimension & $\begin{array}{l}\text { passed or } 500 \text { feet } \\
\text { ahead, same side }\end{array}$ & $\begin{array}{l}\text { Estimate average building height of buildings on same side of street based on proportion of } \\
\text { street fronted by each building. Only estimate building heights for buildings that have been } \\
\text { counted, that front along the street, and are within } 500 \text { feet from the camera at the end of the } \\
\text { video clip. Use } 0 \text { if there are no buildings that front along street. Only estimate the height of } \\
\text { building that you can see if the camera does not pan the entire height of the building. Assume } \\
\text { that the height for } 1 \text { typical storey is } 10 \text { feet. }\end{array}$ \\
\hline building height to width ratio - same side & ratio & $\begin{array}{l}\text { passed or } 500 \text { feet } \\
\text { ahead, same side }\end{array}$ & $\begin{array}{l}\text { Estimate average width of buildings on same side. Only estimate the ratio for buildings that } \\
\text { have been counted, that front along the street, and are within } 500 \text { feet from the camera at the } \\
\text { end of the video clip. Divide average height of buildings on same side by average width of } \\
\text { buildings on same side. }\end{array}$ \\
\hline building height - opposite side & dimension & $\begin{array}{l}\text { passed or } 500 \text { feet } \\
\text { ahead, opposite } \\
\text { side }\end{array}$ & $\begin{array}{l}\text { Estimate average building height of buildings on opposite side of street. Only estimate building } \\
\text { heights for buildings that have been counted, that front along the street, and are within } 500 \\
\text { feet from the camera at the end of the video clip. Use } 0 \text { if there are no buildings that front } \\
\text { along street. Only estimate the height of building that you can see if the camera does not pan } \\
\text { the entire height of the building. Assume that the height for } 1 \text { typical storey is } 10 \text { feet. }\end{array}$ \\
\hline common building heights - both sides & $\begin{array}{l}\text { dummy } \\
1=\text { yes } 0=\text { no }\end{array}$ & $\begin{array}{l}\text { no more than } 30 \% \\
\text { variance for } \\
\text { buildings fronting } \\
\text { along street and } \\
\text { passed or } 500 \text { feet } \\
\text { ahead, both sides }\end{array}$ & $\begin{array}{l}\text { Indicate whether buildings have common buildiing heights. Common building heights occur } \\
\text { when the height of all buildings that have been counted, that front along the street, and are } \\
\text { within } 500 \text { feet from the camera at the end of video clip varies no more than } 30 \% \text {. }\end{array}$ \\
\hline common building masses - both sides & $\begin{array}{l}\text { dummy } \\
1=\text { yes } 0=\text { no }\end{array}$ & $\begin{array}{l}\text { no more than } 30 \% \\
\text { variance for } \\
\text { buildings fronting } \\
\text { along street and } \\
\text { passed or } 500 \text { feet } \\
\text { ahead, both sides }\end{array}$ & $\begin{array}{l}\text { Indicate whether buildings have common building masses. Common mass occurs when when } \\
\text { the mass of all buildings that have been counted, that front along the street, and are within } \\
500 \text { feet from the camera at the end of video clip varies no more than } 30 \% \text {. }\end{array}$ \\
\hline street width & dimension & $\begin{array}{l}\text { average of passed } \\
\text { or } 50 \text { feet ahead }\end{array}$ & $\begin{array}{l}\text { Estimate street width. Street width includes frontage roads and/or parking aisles. Assume that } \\
\text { a typical parking lane is } 8 \text { feet and a typical travel lane is } 12 \text { feet. If the median between a one } \\
\text { way pair is more than } 50 \text { feet wide, treat each couplet as seperate streets. Only consider the } \\
\text { width of the adjacent half street. }\end{array}$ \\
\hline median width & dimension & $\begin{array}{l}\text { average of passed } \\
\text { or } 50 \text { feet ahead }\end{array}$ & Estimate median width if one is present. Medians should be raised in order to be considered. \\
\hline
\end{tabular}




\begin{tabular}{|c|c|c|c|}
\hline sidewalk width - same side & dimension & $\begin{array}{l}\text { average of passed } \\
\text { or } 50 \text { feet ahead, } \\
\text { same side }\end{array}$ & Estimate total sidewalk width. Estimate average if sidewalk width varies. \\
\hline
\end{tabular}
building face distance varies, estimate an average. Compute average of building heights of both sides of street. Divide by total width of street including street, median, sidewalks, and

building height to street widh ratio ratio average setback from sidewalk.

\begin{tabular}{|c|c|c|c|}
\hline sidewalk clear width - same side & dimension & $\begin{array}{l}\text { average of passed } \\
\text { or } 50 \text { feet ahead, } \\
\text { same side }\end{array}$ & Estimate width of sidewalk with no obstructions. \\
\hline buffer width - same side & dimension & $\begin{array}{l}\text { average of passed } \\
\text { or } 50 \text { feet ahead, } \\
\text { same side }\end{array}$ & $\begin{array}{l}\text { Estimate width from outside clear width to moving cars. (distance between moving cars and } \\
\text { the portion of the sidewalk where pedestrians are most likely to walk). }\end{array}$ \\
\hline
\end{tabular}

Count number of different paving materials for the street, the sidewalk on same side, and passed or 50 feet surfaces connected to the sidewalk on same side. Paving material categories are asphalt, $\underline{\text { number of paving materials }}$ count passed
ahead concrete, colored concrete, brick, paver, and aggregate.

types of paving materials

textured sidewalk surface - same side text

dummy

dummy
$1=$ yes $0=$ no
List counted paving materials.

Indicate the presence of a textured sidewalk. Textured sidewalks or streets are composed of materials that have patterns (brick, pavers, stamped asphalt, patterned or stameped concrete). The patterned materials usually resemble brick and are used to visually break up sidewalk or street. A sidewalk or street will be considered textured if at least $50 \%$ of the 
$\underline{\text { textured street surface }}$

dummy

$1=$ yes $0=$ no

Indicate the presence of a textured street. Textured sidewalks or streets are composed of materials that have patterns (brick, pavers, stamped asphalt, patterned or stameped

concrete). The patterned materials usually resemble brick and are used to visually break up

passed or 50 feet sidewalk or street. A sidewalk or street will be considered textured if at least $50 \%$ of the ahead surface is textured.

pavement condition

rating

passed or 50 feet patches, presence of weeds, etc... Rate the condition of the sidewalk on the same side and

Rate pavement condition on a 1-5 Likert scale taking note of visible cracks, discoloration, the street. 


$\begin{array}{ll} & \text { dummy } \\ \text { overhead utilities } & 1=\text { yes } 0=n\end{array}$

number of landscape elements - both sides
Indicate the presence of overhead utility lines

Count each type of tree, bush, and visible groundcover. Distinguish between trees in natural settings vs. trees in wells or landscaped beds, evergreen trees vs deciduous, small trees vs.

$20 \%$ screen

height, both sides; tall trees. Note the occurences of bushes and/or hedges and turf. Only count landscape

or within 50 feet, $\quad$ elements that either occupy at least $20 \%$ of screen height or are within 50 feet from the same side 
large planters without trees - same side count count small planters - same side

counted landscape landscape condition rating+B7 same side at least 10 square

feet and within 50 Count number of large landscaping beds with shrubs or flowers that are more than 10 square feet, same side

less than $10 \quad$ Count number of small planting pots with shrubs or flowers that are less than 10 square feet square feet and and within 50 feet from the camera. Small planters should be permanent elements of the within 50 feet, streetscape and not pots that are taken in at the end of the day. Do not count small planters that are indoors and can be seen through windows. spacing occurs when the spacing of trees varies no more than $30 \%$. and lack of adequate landscaping. 


\begin{tabular}{lll} 
& likert scale & \\
1 very quiet, & 5 very loud & Estimate the noise level taking note of noise from traffic, pedestrians, and any other ambient \\
noise level & noises. & \\
\hline
\end{tabular}

outdoor dining - same side

tables - same side within 50 feet,

same side
Count the number of distinct places that provide outdoor dining. Count outdoor dining areas even if there are no diners. However do not count outdoor dining if the dining area appears closed (umbrellas folded up, chairs on tables).

\section{dummy}

$1=$ yes $0=$ no
Count outdoor dining tables as well as other tables that are within 50 feet from the camera.

Count number of seats that are within 50 feet from the camera. Seats around private dining do within 50 feet, not count as seats. Only count public seating. Factor in seating on planters, walls, bus stops, etc.. 


\begin{tabular}{|c|c|c|c|}
\hline$\underline{\text { miscellaneous street items - same side }}$ & count & $\begin{array}{l}\text { within } 50 \text { feet, } \\
\text { same side }\end{array}$ & $\begin{array}{l}\text { Count miscellaneous street items that are within } 50 \text { feet from the camera. Count hydrants, } \\
\text { flags, banners, merchandise stands, street vendors, atms, hanging plants, flower pots, } \\
\text { umbrellas, etc... }\end{array}$ \\
\hline $\begin{array}{l}\text { types of miscellaneous street items - same } \\
\text { side }\end{array}$ & text & & List miscellaneous street items counted. \\
\hline public art - both sides & count & $\begin{array}{l}20 \% \text { screen } \\
\text { height, both sides; } \\
\text { or within } 50 \text { feet, } \\
\text { same side }\end{array}$ & Count pieces of public art (sculptures, murals, etc..) that occupy at least $20 \%$ of screen height. \\
\hline
\end{tabular}




\begin{tabular}{ll}
\hline count & same side \\
& \\
& $20 \%$ screen \\
height, both
\end{tabular}

billboards

common signage graffiti height, both sides;

count

or within 50 feet,

Count billboards that occupy at least $20 \%$ of screen height or are within 50 feet from the same side camera. dummy

$1=$ yes $0=$ no

counted signs

Indicate the presence of common signage. Common signage occurs when counted signs appear to have the same design.

\section{$20 \%$ screen}

height, both sides

or within 50 feet, $\begin{array}{ll}\text { dummy } & \text { or within } 50 \\ 1=\text { yes } 0=\text { no } & \text { same side }\end{array}$

Count directional signage oriented to the pedestrian that are within 50 feet from the camera.

\author{
Indicate the presence of graffiti.
}




\section{view landscaping ahead}

proportion

view other ahead

proportion
Pause video at initial view down street. Estimate proportion of screen that is landscaping Estimate proporitions in increments of 0.05

Pause video at initial view down street. Estimate proportion of screen that is occupied by elements that cannot be categorized as sky, buildings, pavement, cars, street furniture, or landscaping (for example, people, free standing signs). Estimate proportions in increments of 0.05 . 

proporitions in increments of 0.05 proporitions in increments of 0.05

Pause video at initial view across street. Estimate proporiton of screen that is street furniture. Pedestrian scale street lights, tables, seating, other street furniture, other miscellaneous street 


\section{Appendix 4: Relationships Between Urban Design Qualities and Physical Features}

(hypothesized in regular type and validated in bold)

\begin{tabular}{|c|c|c|c|c|c|c|c|c|c|}
\hline Variable & 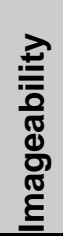 & 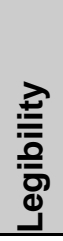 & 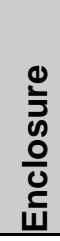 & 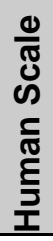 & 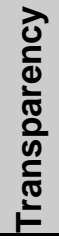 & 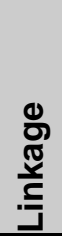 & $\begin{array}{l}\frac{\lambda}{x} \\
\frac{\partial}{0} \\
\frac{0}{\varepsilon} \\
0 \\
0\end{array}$ & $\begin{array}{l}\text { U } \\
\frac{0}{0} \\
\frac{0}{d} \\
\frac{C}{0} \\
\mathcal{U}\end{array}$ & 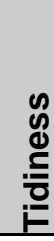 \\
\hline courtyards/plazas/parks - both sides & $\mathbf{X}$ & & $\mathrm{X}$ & & $\mathrm{X}$ & & $\mathrm{X}$ & & \\
\hline arcade - same side & & & $\mathrm{X}$ & $\mathrm{X}$ & $\mathrm{X}$ & $\mathrm{X}$ & & & \\
\hline landmarks - both sides & $\mathrm{X}$ & $\mathrm{X}$ & & & & & & & \\
\hline major landscape features - both sides & $\mathbf{X}$ & $\mathrm{X}$ & & & & & & & \\
\hline memorable architecture & $\mathrm{X}$ & $\mathbf{X}$ & & & & & & & \\
\hline distinctive signage & $\mathrm{X}$ & $\mathrm{X}$ & & & & & & & \\
\hline long sight lines & & $\mathrm{X}$ & $\mathbf{X}$ & $\mathbf{X}$ & & $\mathrm{X}$ & & & \\
\hline terminated vista & $\mathrm{X}$ & $\mathbf{X}$ & $\mathrm{X}$ & $\mathrm{X}$ & & $\mathrm{X}$ & & & \\
\hline progress toward next intersection & & & & $\mathrm{X}$ & & $\mathrm{X}$ & & & \\
\hline proportion of distance walked versus distance visible & & & & $\mathrm{X}$ & & $\mathrm{X}$ & & & \\
\hline street connections to elsewhere & & $\mathrm{X}$ & & & & $\mathbf{X}$ & & & \\
\hline number of buildings - both sides & & & & & & & $\mathbf{X}$ & & \\
\hline number of land uses - both sides & & & & & & & $\mathrm{X}$ & & \\
\hline proportion of historic building frontage - both sides & $\mathbf{X}$ & & & & & & & & \\
\hline number of buildings with identifiers - both sides & $\mathbf{X}$ & $\mathbf{X}$ & & & & & & & \\
\hline \multicolumn{10}{|l|}{ proportion of building frontage with identifiers } \\
\hline various building ages & & & & & & & $\mathrm{X}$ & $\mathrm{X}$ & \\
\hline number of primary building materials & & & & & & & $\mathrm{X}$ & $\mathrm{X}$ & \\
\hline number of dominant building colors & $\mathrm{X}$ & & & & & & $\mathbf{X}$ & $\mathrm{X}$ & \\
\hline number of accent colors - both sides & & & & & & & $\mathbf{X}$ & $\mathrm{X}$ & \\
\hline building projections - same side & & & & & & $\mathrm{X}$ & $\mathrm{X}$ & & \\
\hline visible sets of doors - same side & & & & $\mathrm{X}$ & $\mathbf{X}$ & $\mathbf{X}$ & $\mathrm{X}$ & & \\
\hline
\end{tabular}




\begin{tabular}{|c|c|c|c|c|c|c|c|c|c|}
\hline Variable & 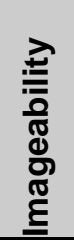 & 를 & 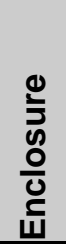 & 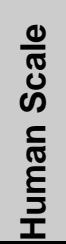 & 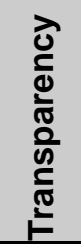 & 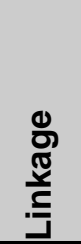 & 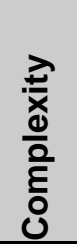 & 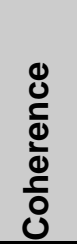 & 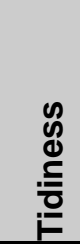 \\
\hline proportion of counted sets of doors that are recessed & & & & & & $\mathbf{X}$ & & & \\
\hline proportion first floor facade with windows & & & & $\mathbf{X}$ & $\mathrm{x}$ & & & & \\
\hline proportion entire facade with windows & & & & $\mathrm{x}$ & $\mathbf{x}$ & & & & \\
\hline common window proportions - both sides & & & & & & & & $\mathrm{X}$ & \\
\hline awnings or overhangs - both sides & & & $\mathrm{X}$ & $\mathrm{x}$ & & $\mathrm{X}$ & $\mathrm{X}$ & & \\
\hline height interruptions - same side & & & & $\mathrm{x}$ & & & & & \\
\hline number of buildings with non-rectangular silhouettes & $\mathrm{X}$ & & & & & & $\mathrm{x}$ & & \\
\hline proportion of buildings with non-rectangular silhouettes & $\mathrm{X}$ & & & & & & & & \\
\hline common architectural style - both sides & & & & & & $\mathrm{X}$ & & $\mathrm{X}$ & \\
\hline common materials - both sides & & & & & & & & $\mathrm{x}$ & \\
\hline proportion active uses - same side & & & & $\mathbf{X}$ & $\mathbf{X}$ & & $x$ & & \\
\hline proportion street wall - same side & & & $\mathrm{X}$ & & $\mathbf{x}$ & & & & \\
\hline proportion street wall - opposite side & & & $\mathrm{X}$ & & & & & & \\
\hline enclosed sides & & & $\mathrm{X}$ & & & & & & \\
\hline average building setback & & & & & $\mathrm{x}$ & & & & \\
\hline common setbacks - both sides & & & $\mathrm{X}$ & & & & & $\mathrm{X}$ & \\
\hline building height - same side & & & $\mathrm{X}$ & $\mathbf{X}$ & $x$ & & & & \\
\hline building height to width ratio - same side & & & & $\mathrm{X}$ & & & & & \\
\hline building height - opposite side & & & $\mathrm{X}$ & $\mathrm{X}$ & & & & & \\
\hline common building heights - both sides & & & $\mathrm{x}$ & & & $\mathrm{X}$ & & $x$ & \\
\hline common building masses - both sides & & & & & & & & $x$ & \\
\hline street width & & & $\mathrm{X}$ & $\mathrm{X}$ & & $\mathrm{X}$ & & & \\
\hline median width & & & & $\mathrm{X}$ & & & & & \\
\hline sidewalk width - same side & & & & & $\mathrm{x}$ & & & & \\
\hline building height to street width ratio & & & $\mathrm{x}$ & & & & & & \\
\hline
\end{tabular}




\begin{tabular}{|c|c|c|c|c|c|c|c|c|c|}
\hline Variable & 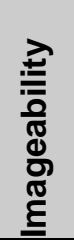 & 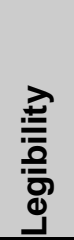 & 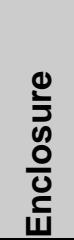 & 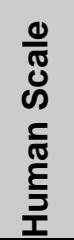 & 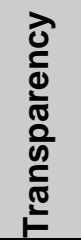 & 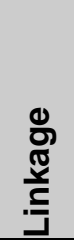 & $\frac{\overrightarrow{7}}{\frac{\lambda}{0}}$ & 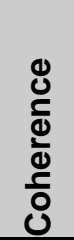 & 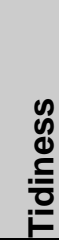 \\
\hline sidewalk clear width - same side & & & & $\mathrm{X}$ & & & & & \\
\hline buffer width - same side & & & & $\mathrm{X}$ & & & & & \\
\hline number of paving materials & & & & & & & $\mathrm{X}$ & $\mathrm{X}$ & \\
\hline textured sidewalk - same side & & & & $\mathrm{X}$ & & $\mathrm{X}$ & $\mathrm{X}$ & & \\
\hline textured street & & & & $\mathrm{X}$ & & $\mathrm{X}$ & $\mathrm{X}$ & & \\
\hline pavement condition & & & & & & & & & $\mathbf{x}$ \\
\hline debris condition & & & & & & & & & $\mathrm{X}$ \\
\hline parked cars - same side & & & & & & & $\mathrm{X}$ & & \\
\hline proportion of street with parked cars - same side & & & $\mathrm{x}$ & $\mathrm{X}$ & & & & & \\
\hline moving cars - both sides & & & & $\mathrm{X}$ & & $\mathrm{X}$ & $\mathrm{X}$ & & \\
\hline speed & & & & $\mathrm{X}$ & & & & & \\
\hline traffic to street width ratio & & & & $\mathrm{X}$ & & & & & \\
\hline moving cyclists - both sides & & & & $\mathrm{X}$ & & & $\mathrm{X}$ & & \\
\hline curb extensions - same side & & & & $\mathrm{X}$ & & $\mathrm{X}$ & $\mathrm{X}$ & & \\
\hline midblock crossings & & & & $\mathrm{X}$ & & $\mathrm{X}$ & $\mathrm{X}$ & & \\
\hline midblock passageways - same side & & & & $\mathrm{X}$ & $\mathrm{x}$ & $\mathrm{X}$ & $\mathrm{X}$ & & \\
\hline overhead utilities & & & & & & & $\mathrm{X}$ & & $\mathrm{X}$ \\
\hline number of landscape elements - both sides & & & & & & & $\mathrm{X}$ & & \\
\hline landscaped median & & & & $\mathrm{X}$ & & $\mathrm{x}$ & $\mathrm{X}$ & & \\
\hline number of trees - both sides & & & $\mathrm{x}$ & $\mathrm{X}$ & & & $\mathrm{X}$ & & \\
\hline trees in wells or landscaped beds - same side & & & & $\mathrm{X}$ & & & $\mathrm{X}$ & & \\
\hline proportion of sidewalk shaded by trees - same side & & & $\mathrm{X}$ & & & & & & \\
\hline large planters without trees - same side & & & & $\mathrm{X}$ & & & $\mathrm{X}$ & & \\
\hline small planters - same side & & & & $\mathbf{X}$ & & & $\mathrm{X}$ & & \\
\hline landscape condition & & & & & & & & & $\mathbf{X}$ \\
\hline
\end{tabular}




\begin{tabular}{|c|c|c|c|c|c|c|c|c|c|}
\hline Variable & 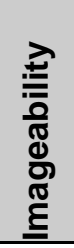 & 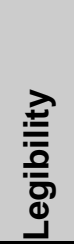 & 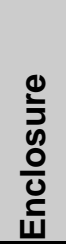 & 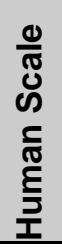 &  & 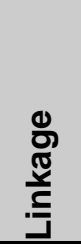 & 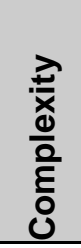 & 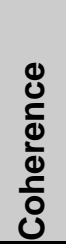 & 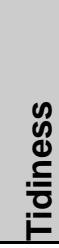 \\
\hline common tree spacing and type - same side & & $\mathbf{X}$ & & & & & & $\mathrm{x}$ & $x$ \\
\hline common tree spacing and type - both sides & & $\mathrm{X}$ & & & & $\mathrm{X}$ & & $\mathbf{X}$ & $x$ \\
\hline pedestrians moving - same side & $\mathbf{X}$ & & & $\mathrm{x}$ & & & $\mathbf{X}$ & $\mathbf{X}$ & \\
\hline stationary people standing - same side & $\mathrm{X}$ & & & $\mathrm{x}$ & & & $\mathrm{x}$ & & \\
\hline people seated - same side & $\mathrm{X}$ & & & $\mathrm{x}$ & $\mathrm{x}$ & & $\mathrm{x}$ & & \\
\hline noise level & $\mathbf{X}$ & & & $x$ & & & $\mathrm{x}$ & & \\
\hline outdoor dining - same side & $\mathrm{X}$ & & & $x$ & $x$ & $\mathrm{X}$ & $\mathbf{x}$ & & \\
\hline tables - same side & & & & $\mathrm{x}$ & & & $\mathrm{x}$ & & \\
\hline seats - same side & & & & $\mathrm{x}$ & & & $\mathrm{X}$ & & \\
\hline pedestrian scale street lights - both sides & & & $\mathrm{X}$ & $x$ & & & $\mathrm{x}$ & $\mathbf{X}$ & \\
\hline other street furniture - same side & & & & $\mathrm{x}$ & & & $\mathrm{X}$ & $\mathrm{X}$ & $\mathrm{x}$ \\
\hline miscellaneous street items - same side & & & & $\mathrm{X}$ & & & $\mathrm{x}$ & & $x$ \\
\hline public art - both sides & $\mathrm{X}$ & $\mathbf{X}$ & & $\mathrm{x}$ & & & $\mathbf{X}$ & & \\
\hline traffic signs - same side or median & & & & & & & $\mathrm{X}$ & $\mathrm{X}$ & $x$ \\
\hline place/building/business signs - same side & & $\mathbf{X}$ & & & & & $\mathrm{x}$ & $\mathrm{X}$ & $x$ \\
\hline directional signage - same side & & $\mathrm{X}$ & & & & & $\mathrm{x}$ & & \\
\hline billboards & $\mathrm{X}$ & & & $\mathrm{x}$ & & & $\mathrm{X}$ & & $x$ \\
\hline common signage & & & & & & $\mathrm{x}$ & & $\mathrm{X}$ & \\
\hline graffiti & & & & & & & $\mathrm{X}$ & & $\mathrm{x}$ \\
\hline sky ahead & & & $\mathbf{X}$ & & & & & & \\
\hline buildings ahead & & & $\mathrm{X}$ & & & & & & \\
\hline \multicolumn{10}{|l|}{ pavement ahead } \\
\hline \multicolumn{10}{|l|}{ cars ahead } \\
\hline street furniture ahead & & & & & & & & & $\mathrm{x}$ \\
\hline landscaping ahead & & & $\mathrm{x}$ & & & & & & $\mathrm{x}$ \\
\hline
\end{tabular}




\begin{tabular}{|c|c|c|c|c|c|c|c|c|c|}
\hline Variable & 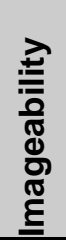 & 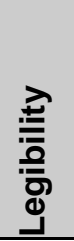 & 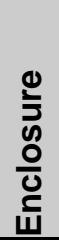 & 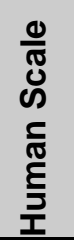 & 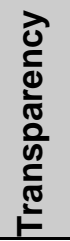 & 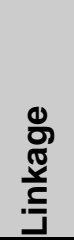 & $\begin{array}{l}\frac{\lambda}{x} \\
\frac{0}{0} \\
\frac{0}{0} \\
0 \\
0\end{array}$ & 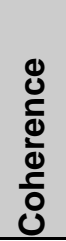 & 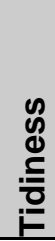 \\
\hline sky across & & & $x$ & & & & & & \\
\hline buildings across & & & $\mathrm{X}$ & & & & & & \\
\hline
\end{tabular}

pavement across

cars across

street furniture across

landscaping across

maximum ahead

$\mathrm{X}$

maximum across 


\section{Appendix 5: References}

Alexander, C., S. Ishikawa, and M. Silverstein. 1977. A Pattern Language - Towns Buildings Construction. Oxford University Press, New York.

Christopher Alexander. 1965 (April). A City is Not a Tree. Architectural Forum. 122 (No 1\&2): 58-62.

Appleyard, D. 1981. Livable Streets. University of California Press, Berkeley, CA.

Arnheim, R. 1977. Dynamics of Architectural Form. University of California Press, Berkeley, CA.

Arnold, H. 1993. Trees in Urban Design. Van Nostrand Reinhold, New York.

Bacon, E. 1974. Design of Cities, Viking Press, New York.

Blumenfeld, H. 1953 (April). Scale in Civic Design, Town Planning Review. 24: 35-46.

Cullen, G. 1961. The Concise Townscape. Reed Educational and Professional Publishing, London.

Duany, A. and E. Plater-Zyberk. 1992. The Second Coming of the American Small Town. Wilson Quarterly. 16: 19-48

Elshestaway, Y. 1997. Urban Complexity: Toward the measurement of the physical complexity of streetscapes. Journal of Architectural and Planning Research. 14: 301-316.

Ewing, R. 1996. Pedestrian- and Transit-Friendly Design. Tallahaseee, FL.

Ewing, R. 2000. Asking Transit Users about Transit-Oriented Design. Transportation Research Record. 1735: 19-24.

Ewing, R. 2005. Can the Physical Environment Determine Physical Activity Levels? Exercise and Sport Sciences Review, pages not assigned.

Ewing, R. (in press) Turning Highways into Main Streets: Two Innovations in Planning Methodology. Journal of the American Planning Association.

Ewing, R. and R. Cervero. 2001. Travel and the Built Environment. Transportation Research Record 1780: 87-114. 
Gehl, J. 1987. Life Between Buildings-Using Public Space, Van Nostand Reinhold, New York.

Handy, S. 1992. Regional versus Local Accessibility: Variations in Suburban Form and the Effects on Nonwork Travel. Unpublished dissertation, University of California Berkeley.

Handy, S. 2004. Critical Assessment of the Literature on the Relationships Among Transportation, Land Use, and Physical Activity.

Heath, T, S. Smith, and B. Lim. 2000. The Complexity of Tall Building Facades. Journal of Architectural and Planning Research. 17(3): 206-220.

Hedman, R. 1984. Fundamentals of Urban Design, American Planning Association, Chicago, IL.

Herzog, T.R., S. Kaplan, and R. Kaplan. 1982. The Prediction of Preference for Unfamiliar Urban Places. Population and Environment. 5(1): 43-59.

Herzog, T.R. and O.L. Leverich. 2003. Searching for Legibility. Environment and Behavior. 35(4): 459-477.

Jacobs, A. 1993. Great Streets. MIT Press, Cambridge, MA.

Jacobs, A. and D. Appleyard. 1987. Toward an Urban Design Manifesto. Journal of the American Planning Association. 53: 112120.

Jacobs, J. 1961. The Death and Life of Great American Cities. Random House, New York.

Kaplan, R. and S. Kaplan. 1989. The Experience of Nature-A Psychological Perspective. Cambridge University Press, New York.

Kay, J.H. (1997) Asphalt Nation: How the Automobile Took over America, and How We Can Take It Back. University of California Press, Berkeley.

Landis, J.R. and G.G. Koch. 1977. The Measurement of Observer Agreement for Categorical Data. Biometrics. 33: $159-174$.

Lennard, S.H.C. and H.L. Lennard, Livable Cities-People and Places: Social and Design Principles for the Future of the City, Center for Urban Well-Being, Southhampton, New York, 1987. 
Lynch, K. 1960. The Image of the City. J oint Center for Urban Studies, Cambridge, MA.

Nasar, J.L. 1987. The effect of sign complexity and coherence on the perceived quality of retail scenes. Journal of the American Planning Association. 53: 499-509.

Nelessen, A. 1994. Visions for a New American Dream. American Planning Association, Washington, D.C.

Rapoport, A. 1990. History and Precedent in Environmental Design. Kluwer Academic Publishers, Plenum Press, New York.

Raudenbush S.W., A. Bryk, and R. Congdon. 2004. HLM 6: Hierarchical Linear \& Nonlinear Modeling. Scientific Software International, Chicago, IL.

Sitte, C. 1889. City Planning According to Artistic Principles. Verlag von Carl Graeser, Vienna (complete translation in G.R. Collins, C.C. Collins, Camillo Sitte. 1986. The Birth of Modern City Planning. Rizzoli International Publications, New York).

Stamps, A.E. 1998. Measures of Architectural Mass: From Vague Impressions to Definite Design Features. Environment and Planning B. 25: 825-836.

Stamps, A.E. 1999. Sex, Complexity, and Preferences for Residential Facades. Perceptual and Motor Skills. 88: $1301-1312$.

Trancik, R. 1986. Finding Lost Space-Theories of Urban Design. Van Nostrand Reinhold, New York.

Tunnard, C. and B. Pushkarev. 1963. Man-Made America-Chaos or Control? Yale University Press, New Haven, CT.

Unwin, R. 1909. Town Planning in Practice. T. Fisher Unwin, Ltd., London (reissued by Princeton Architectural Press: New York, 1994).

Whyte, W.H. 1988. City-Rediscovering the Center. Doubleday, New York. 